\title{
Inducible and reversible inhibition of miRNA-mediated gene repression in vivo
}

\author{
Gaspare La Rocca ${ }^{1 *+}$, Bryan King ${ }^{1 \dagger}$, Bing Shui ${ }^{2}$, Xiaoyi Li ${ }^{1,3}$, Minsi Zhang ${ }^{1}$, \\ Kemal M Akat ${ }^{4}$, Paul Ogrodowski ${ }^{1}$, Chiara Mastroleo ${ }^{1}$, Kevin Chen ${ }^{1}$, \\ Vincenzo Cavalieri ${ }^{5}$, Yilun $\mathrm{Ma}^{6}$, Viviana Anelli ${ }^{7}$, Doron Betel $^{8}$, Joana Vidigal ${ }^{9}$, \\ Thomas Tuschl ${ }^{4}$, Gunter Meister ${ }^{10}$, Craig B Thompson ${ }^{1}$, Tullia Lindsten ${ }^{11}$, \\ Kevin Haigis ${ }^{2}$, Andrea Ventura ${ }^{1 *}$
}

${ }^{1}$ Cancer Biology and Genetics Program, Memorial Sloan Kettering Cancer Center, New York, United States; ${ }^{2}$ Department of Cancer Biology, Dana Farber Cancer Institute, Boston, United States; ${ }^{3}$ Louis V. Gerstner Jr. Graduate School of Biomedical Sciences, Memorial Sloan Kettering Cancer Center, New York, United States; ${ }^{4}$ Laboratory of RNA Molecular Biology, The Rockefeller University, New York, United States; ${ }^{5}$ Department of Biological, Chemical and Pharmaceutical Sciences and Technologies, University of Palermo, Palermo, Italy; ${ }^{6}$ Weill Cornell/Rockefeller/SloanKettering Tri-Institutional MD-PhD Program, New York, United States; ${ }^{7}$ Center of

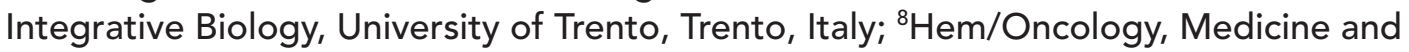
Institution for Computational Biomedicine, Weill Cornell Medical College, New York, United States; ${ }^{9}$ Laboratory of Biochemistry and Molecular Biology, National Cancer Institute, Bethesda, United States; ${ }^{10}$ Regensburg Center for Biochemistry, University of Regensburg, Regensburg, Germany; ${ }^{11}$ Immunology Program, Memorial Sloan Kettering Cancer Center, New York, United States

*For correspondence: laroccag@mskcc.org (GLR); venturaa@mskcc.org (AV)

'These authors contributed equally to this work

Competing interest: See page 24

Funding: See page 24

Preprinted: 01 June 2021 Received: 03 June 2021

Accepted: 24 August 2021

Published: 31 August 2021

Reviewing Editor: Ashish Lal, National Institutes of Health, United States

(c) Copyright La Rocca et al. This article is distributed under the terms of the Creative Commons Attribution License, which permits unrestricted use and redistribution provided that the original author and source are credited.

\begin{abstract}
Although virtually all gene networks are predicted to be controlled by miRNAs, the contribution of this important layer of gene regulation to tissue homeostasis in adult animals remains unclear. Gain and loss-of-function experiments have provided key insights into the specific function of individual miRNAs, but effective genetic tools to study the functional consequences of global inhibition of miRNA activity in vivo are lacking. Here we report the generation and characterization of a genetically engineered mouse strain in which miRNA-mediated gene repression can be reversibly inhibited without affecting miRNA biogenesis or abundance. We demonstrate the usefulness of this strategy by investigating the consequences of acute inhibition of miRNA function in adult animals. We find that different tissues and organs respond differently to global loss of miRNA function. While miRNA-mediated gene repression is essential for the homeostasis of the heart and the skeletal muscle, it is largely dispensable in the majority of other organs. Even in tissues where it is not required for homeostasis, such as the intestine and hematopoietic system, miRNA activity can become essential during regeneration following acute injury. These data support a model where many metazoan tissues primarily rely on miRNA function to respond to potentially pathogenic events.
\end{abstract}

\section{Introduction}

MicroRNAs (miRNAs) are short non-coding RNAs that in Metazoa repress gene expression at the post-transcriptional level by binding to partially complementary sequences on target mRNAs (Bartel, 2009; Bartel, 2018; Eichhorn et al., 2014; Izaurralde, 2015). 
miRNAs act as part of a large ribonucleoprotein complex known as the miRNA-induced silencing complex (miRISC). In mammals, the Argonaute protein family (AGO1-4) and the trinucleotide repeatcontaining gene 6 protein family (TNRC6A/GW182, TNRC6B and TNRC6C) are the core components of the miRISC. AGO binds to the miRNA and facilitates its interaction with target mRNAs (Schirle et al., 2014). In turn, TNRC6 binds to AGO and recruits the decapping and deadenylation complexes, leading to degradation of target mRNAs (Braun et al., 2011; Chekulaeva et al., 2011; Chen et al., 2009; Chen et al., 2014; Fabian et al., 2011; Guo et al., 2010a; Huntzinger et al., 2013; Lazzaretti et al., 2009; Nishihara et al., 2013; Rehwinkel et al., 2005; Till et al., 2007).

Although miRNAs are abundantly expressed in embryonic and adult mouse tissues, and computational and experimental analyses indicate that they target components of virtually every cellular process (Flynt and Lai, 2008), animals harboring targeted deletion of single miRNA genes are often indistinguishable from their wild-type counterparts (Abdellatif, 2012; Chivukula et al., 2014; Cimmino et al., 2005; Liu et al., 2008; Park et al., 2010; van Rooij et al., 2007; Vechetti et al., 2019; Williams et al., 2009). One explanation for these observations is that the redundant functions of related miRNAs may buffer the emergence of obvious phenotypes in mutant animals (Bartel, 2009; Bartel, 2018). Interestingly, however, clear phenotypes often emerge in mutant adult animals when exposed to external or internal perturbations (Chivukula et al., 2014; Mendell and Olson, 2012; van Rooij et al., 2007). These observations suggest that, at least in some contexts, miRNA function is conditionally, rather than constitutively, required to carry on cellular processes.

Previous efforts to investigate the consequences of global inhibition of miRNA function have relied upon the targeted deletion of the core miRNA biogenesis factors DICER, DROSHA, and DGCR8 (Treiber et al., 2019). Several animal models harboring conditional or constitutive knockout alleles of these genes have been generated (Bernstein et al., 2003; Chong et al., 2008; Hebert et al., 2010; Huang et al., 2012; JnBaptiste et al., 2017; Kanellopoulou et al., 2005; Kobayashi et al., 2015; Kumar et al., 2007; Wang et al., 2007). Although these strategies have provided important insights into miRNA biology, they suffer from several limitations.

First, inactivation of these gene products is known to have other consequences in addition to impairing miRNA biogenesis. For instance, DICER is involved in epigenetic regulation in the nucleus in a miRNA-independent manner (Fukagawa et al., 2004; Giles et al., 2010; Gullerova and Proudfoot, 2012; Okamura and Lai, 2008; Song and Rossi, 2017; Tam et al., 2008) and is essential to metabolize transcripts from short interspersed nuclear elements, predominantly Alu RNAs in humans and B1 and B2 RNAs in rodents (Kaneko et al., 2011). DROSHA, on the other hand, regulates the expression of several coding and non-coding RNAs by directly cleaving stem-loop structures embedded within the transcripts (Chong et al., 2010). Furthermore, DICER and DROSHA are also involved in the DNAdamage response (Francia et al., 2012; Michelini et al., 2017), and DGCR8 regulates the maturation of small nucleolar RNAs and of some long non-coding RNAs (Cirera-Salinas et al., 2017; Macias et al., 2015). Consequently, the phenotypes observed in these models cannot be solely attributed to inhibition of miRNA activity.

Another limitation of conditional ablation of miRNA biogenesis genes in vivo is that due to their high stability mature miRNAs can persist for several days after their biogenesis is inhibited. For example, 4 weeks after near complete conditional ablation of Dicer1 in the muscle, the levels of the highest expressed miRNAs were found to be only reduced by $30-40 \%$ and their expression remained substantial even 18 months later (Vechetti et al., 2019). This complicates the interpretation of experiments based on temporally controlled conditional ablation of these biogenesis factors, especially in non-proliferating tissues.

Third, a subset of mammalian miRNAs does not rely on the canonical biosynthesis pathway, and therefore their expression and activity are not affected by inactivation of the core miRNA biogenesis factors (Cheloufi et al., 2010; Chong et al., 2010; Cifuentes et al., 2010; Kim et al., 2016; Okamura et al., 2007; Ruby et al., 2007; Yang and Lai, 2011).

Finally, these genetic approaches are not reversible and therefore these animal models cannot be used to study the effects of transient inhibition of miRNA function.

To circumvent these limitations, we have generated a novel genetically engineered mouse strain that allows inducible and reversible disassembly of the miRISC, thereby achieving controllable inhibition of miRNA-mediated gene repression in vivo without affecting small RNA biogenesis. To address the reliance of adult tissues on miRNA-mediated gene repression, we have used this novel strain to 
investigate the consequences of acute inhibition of the miRISC under homeostatic conditions, and during tissue regeneration.

\section{Results}

\section{Inhibition of the miRNA pathway through peptide-mediated disruption of the miRISC}

Multiple motifs within the $\mathrm{N}$-terminal domain of TNRC6 proteins contain regularly spaced tryptophan residues that mediate the interaction between AGO and TNRC6 by inserting into conserved hydrophobic pockets located on AGO's Piwi domain (Lian et al., 2009; Sheu-Gruttadauria and MacRae, 2018).

A peptide encompassing one of the AGO-interacting motifs of human TNRC6B has been previously employed as an alternative to antibody-based approaches to efficiently pull down all AGO family members from cell and tissue extracts (Hauptmann et al., 2015; Pfaff et al., 2013). This peptide, named T6B, competes with endogenous TNRC6 proteins for binding to AGOs. However, as it lacks the domains necessary for the recruitment of decapping and deadenylation factors, it prevents the assembly of the full miRISC, thus resulting in effective inhibition of miRISC-mediated gene repression in cells (Danner et al., 2017; Hauptmann et al., 2015).

Based on these results, we reasoned that temporally and spatially controlled expression of a T6B transgene in animals would offer the unprecedented opportunity to study the consequences of acute and reversible inhibition of miRNA function in vivo without interfering with miRNA biogenesis or abundance (Figure 1A).

To test the suitability of this approach, we first investigated the dynamics of interaction between T6B and the miRISC in mouse and human cell lines. We employed a previously reported size-exclusion chromatography (SEC)-based assay (La Rocca et al., 2015; Olejniczak et al., 2013) to analyze the molecular weight of AGO-containing complexes in lysates from cells expressing either a doxycyclineinducible FLAG-HA-T6B-YFP fusion protein (hereafter referred to as T6B) or a mutant version (hereafter referred to as T6B ${ }^{\mathrm{Mut}}$ ) incapable of binding to $\mathrm{AGO}$ (Figure 1-figure supplement 1). We reasoned that if T6B expression prevents AGO from stably binding to TNRC6 and its targets, AGO proteins should be detected in fractions corresponding to $\sim 120-130 \mathrm{kDa}$, the sum of the molecular weights of AGO ( 95 kDa) and the T6B fusion protein ( $30 \mathrm{kDa})$. In contrast, unperturbed AGO complexes that are part of the fully assembled miRISC bound to mRNAs should elute in the void of the column, which contains complexes larger than $2 \mathrm{MDa}$ (Figure 1B).

As expected, in lysates from cells expressing no T6B or T6B ${ }^{\text {Mut }}$, AGO2 and TNRC6A were mostly detected in the high-molecular-weight fractions, indicating the presence of target-bound miRISC (Figure 1C). In contrast, AGO2 and TNRC6A were nearly completely depleted from the highmolecular-weight fractions in lysates from cells expressing T6B (Figure 1C). Moreover, while AGO2, TNRC6A, and the polyA-binding protein 1 (PABP1) co-fractionated in lysates from control cells, they eluted in different fractions in lysates from T6B-expressing cells (Figure 1C), indicating that T6B leads to loss of interactions between the miRISC components and mRNAs. As expected based on the strong evolutionary conservation of human and mouse AGO and TNRC6 proteins (Pfaff et al., 2013; Zielezinski and Karlowski, 2015; Zipprich et al., 2009), we obtained identical results when human T6B was expressed in mouse embryo fibroblasts (MEFs; Figure 1-figure supplement 2).

To test whether the redistribution of AGO-containing complexes induced by T6B expression was mirrored by a loss of miRNA-mediated gene repression, we performed RNAseq analysis on MEFs expressing T6B or T6B ${ }^{\text {Mut }}$. Cells expressing T6B displayed marked and selective de-repression of predicted mRNA targets for expressed miRNAs (Figure 1D). The extent of de-repression was roughly proportional to the abundance of individual miRNA families, with predicted targets of poorly expressed miRNAs collectively showing modest de-repression compared to targets of more abundantly expressed miRNA families (Figure 1D). Importantly, de-repression of miRNA targets was not accompanied by a global change in mature miRNAs levels (Figure 1E), consistent with the role of T6B in perturbing the effector step of the miRNA pathway, without affecting miRNA processing.

Of the four mammalian AGO proteins, AGO2 is the only one that has endo-ribonucleolytic activity, which does not require TNRC6 (Liu et al., 2019) and is triggered when the AGO2-loaded small RNA and the target are perfectly complementary (Doench et al., 2003; Liu et al., 2004; Zeng et al., 
A

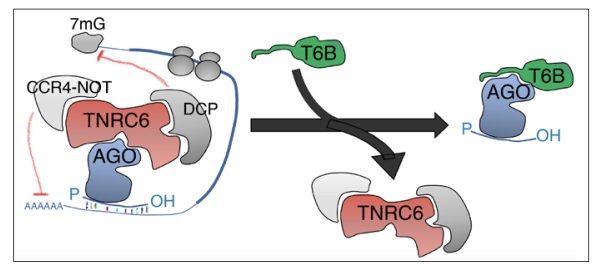

B

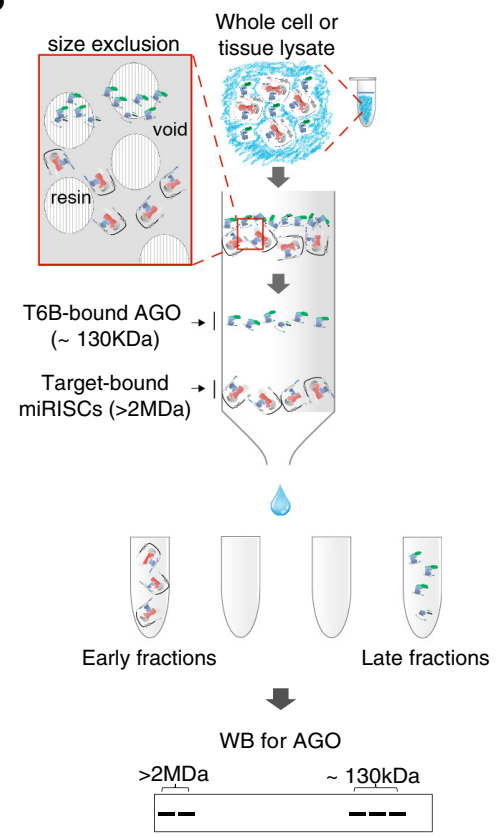

C
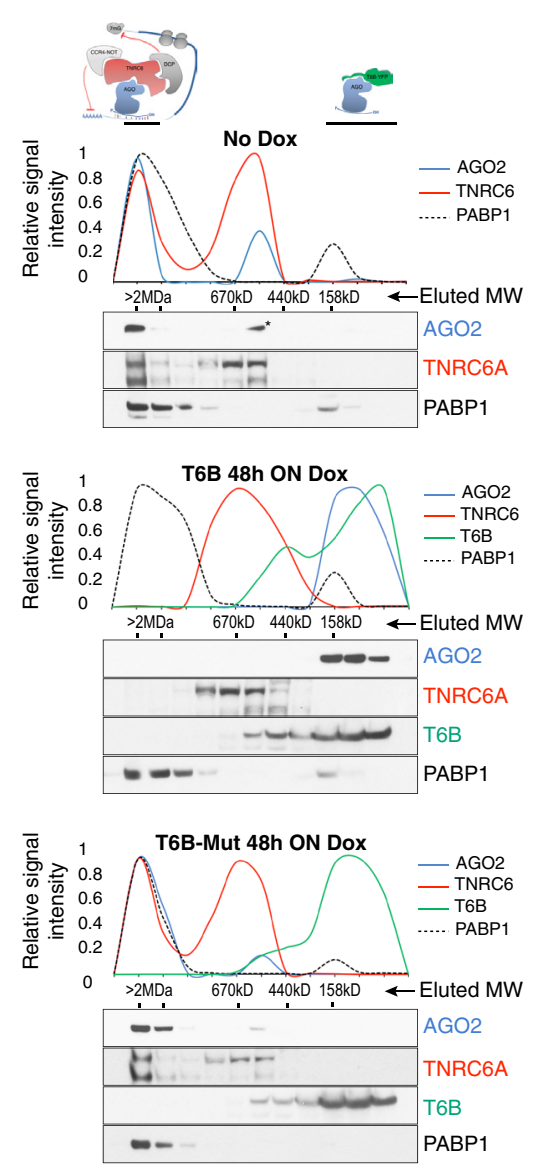

D
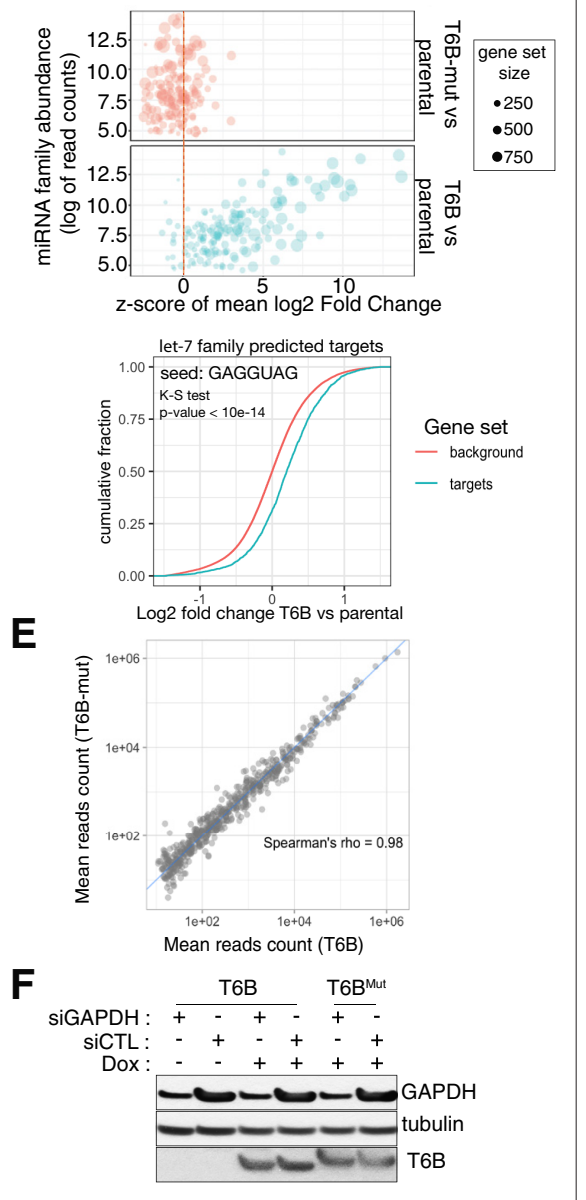

Figure 1. T6B fusion protein prevents miRNA-induced silencing complex (miRISC) assembly and impairs microRNA (miRNA) activity in vitro. (A) Schematics of T6B action: T6B competes with TNRC6 for binding to AGO proteins preventing miRISC assembly. (B) Schematics of the size-exclusion chromatography (SEC) assay for the fractionation of AGO-containing complexes according to their molecular weight. (C) SEC profiling of miRISC components upon T6B expression: total lysates from HCT116 cells expressing no fusion protein (upper panel), T6B (middle panel), or T6B ${ }^{\text {Mut }}$ (lower panel) were fractionated as described in (B) and immunoblotted to detect AGO2, TNRC6A, T6B, and PABP1. For each blot, the relative signal intensity was assessed by densitometric analysis. (D) RNAseq analysis of total and small RNAs isolated from mouse embryo fibroblasts (MEFs) cell lines expressing either no fusion protein, T6B, or T6B ${ }^{\text {Mut }}(n=3$ for each cell line). Upper panel: bubble plot of target de-repression against miRNA abundance. The mean log2-fold change (T6B or T6B ${ }^{\text {Mut }}$ vs. control) of predicted targets for each conserved miRNA family was calculated, converted to a z-score and is plotted on the $x$-axis against the miRNA family abundance (log of the sum of read counts for each member of the family). The size of each circle is proportional to the number of predicted targets. A positive z-score indicates that the targets for that family are preferentially upregulated upon T6B expression, while a negative score would indicate preferential downregulation. Expression of T6B, but not of T6B Mut, causes preferential upregulation of miRNA targets of the most miRNA families and the effect is roughly proportional to each miRNA family abundance. Lower panel: cumulative distribution plot of predicted let-7 targets compared to background in T6B-expressing MEFs. (E) Scatter plots of miRNA abundance as determined by small-RNAseq of total RNA extracted from MEFs expressing either T6B or T6B ${ }^{\text {Mut }}(n=3$ for each cell line). Each dot represents a miRNA in miRbase. (F) Effect of T6B expression on $\mathrm{AGO} 2$ slicing activity. MEFs expressing either T6B or T6B ${ }^{\text {Mut }}$ were transfected with siRNAs targeting GAPDH mRNA (siGAPDH) or with scramble siRNA (siCTL). Levels of GAPDH, T6B, and tubulin were assessed by immunoblot $72 \mathrm{hr}$ post-transfection. T6B and T6B ${ }^{\text {Mut }}$ have slightly different migration on PAGE, as previously observed by Hauptmann et al., 2015.

The online version of this article includes the following figure supplement(s) for figure 1:

Source data 1. RNAseq, differential gene expression, mouse embryo fibroblasts.

Source data 2. z-scores and miRNA family abundance, mouse embryo fibroblasts.

Source data 3. Small RNAseq, microRNA counts, mouse embryo fibroblasts.

Source data 4. Unedited blots shown in Figure 1C.

Source data 5. Unedited blots shown in Figure 1F.

Source data 6. Unedited blots shown in Figure 1F.

Figure 1 continued on next page 
Figure 1 continued

Source data 7. Uncropped blots shown in Figure 1F.

Figure supplement 1. Sequence and properties of the FH-T6B-YFP fusion protein.

Figure supplement 1-source data 1. Unedited blots shown in Figure 1-figure supplement 1.

Figure supplement 1-source data 2. Uncropped blots shown in Figure 1-figure supplement 1.

Figure supplement 2. Size-exclusion chromatography was performed on whole-cell lysates from mouse embryo fibroblasts transduced with retroviral vectors expressing a doxycycline-inducible T6B or T6B Mut transgene and cultured in the presence of doxycycline for $48 \mathrm{hr}$.

Figure supplement 2-source data 1. Unedited blots shown in Figure 1-figure supplement 2.

Figure supplement 2-source data 2. Uncropped blots shown in Figure 1-figure supplement 2.

2003). AGO2's catalytic activity is essential for gene regulation in the germline. For example, in mouse oocytes, AGO2 loaded with endogenous small-interfering RNAs (endo-siRNAs) mediates the cleavage of coding and non-coding transcripts bearing perfectly complementary sequences (Stein et al., 2015; Tam et al., 2008). In metazoan somatic tissues, in contrast, AGO2 catalytic activity is mainly involved in the biogenesis of miR-486 and miR-451 in the hematopoietic system (Cheloufi et al., 2010; Jee et al., 2018), and in occasional instances of miRNA-directed cleavage of mRNAs (Yekta et al., 2004).

Importantly, T6B expression does not interfere with the ability of synthetic siRNAs to cleave perfectly complementary endogenous targets (Figure 1F), indicating that AGO2's catalytic function is not affected by the binding of T6B, and implying that the loading of small RNAs onto AGOs is also not perturbed by T6B.

Collectively these results demonstrate that ectopic T6B expression in mammalian cells causes global inhibition of miRISC function with minimal perturbation of the expression of mature miRNAs, and with preservation of AGO2's endo-nucleolytic activity.

\section{Generation of a mouse strain with inducible expression of a T6B transgene}

To apply this general strategy to an in vivo setting, we next generated mouse embryonic stem cells (mESCs) expressing a doxycycline-inducible T6B transgene. We used a knock-in approach in which the doxycycline-inducible transgene is inserted into the Col1a1 locus of mESC expressing the reverse tetracycline-controlled transactivator (rtTA) under the control of the endogenous Rosa26 promoter (Beard et al., 2006; Figure 2A). Targeted mESCs were tested for the ability to express the T6B transgene in response to doxycycline (Figure 2-figure supplement 1) and then used to generate mice with genotype Rosa26 $6^{\text {rTA/rtAA }}$; Col1a1 ${ }^{\text {T6B/T6B }}$ (hereafter R26 ${ }^{\text {T6B }}$ ). Rosa26 $6^{\text {rtA } / \text { rtTA }}$; Col1a $1^{\text {1/+ }}$ mice, with untargeted Col1a1 loci but expressing rtTA served as negative controls (hereafter R26 $6^{\mathrm{CTL}}$ ).

Upon doxycycline administration, we observed strong expression of T6B in R26 ${ }^{\mathrm{T} 6 \mathrm{~B}}$ mice and across most adult tissues (Figure 2B). Notable exceptions were the central nervous system (Figure 2B, Figure 2-figure supplement 2), probably due to low blood-brain barrier penetration of doxycycline, and the skeletal muscle and the heart, most likely due to low expression of the rtTA transgene in these tissues (Premsrirut et al., 2011).

When doxycycline was administered in the diet, T6B became detectable after $24 \mathrm{hr}$, reached a plateau after 3 days, and completely disappeared 4 days after doxycycline removal from the diet (Figure 2C).

Because colon and liver expressed uniformly high levels of T6B in response to doxycycline, we used these tissues to test the effects of T6B expression on miRISC activity in vivo. Co-IP experiments using antibodies directed to T6B confirmed the interaction between AGO and T6B in these tissues (Figure 2D, Figure 2-figure supplement 3). Expression of T6B resulted in nearly complete disassembly of the miRISC, as indicated by the elution shift of AGO from the high-molecular-weight to lowmolecular-weight fractions in both tissues (Figure 2E, Figure 2-figure supplement 4). Importantly, doxycycline removal from the diet led to a complete reconstitution of the miRISC, as indicated by the reappearance of $\mathrm{AGO} 2$ in the high-molecular-weight fractions (Figure 2E).

To test whether T6B expression also resulted in inhibition of miRNA-mediated gene repression in vivo, we performed RNAseq on total RNAs extracted from the liver and colon of R2 $6^{\mathrm{T} 6 \mathrm{~B}}$ and R26 $6^{\mathrm{CTL}}$ mice kept on doxycycline-containing diet for 1 week. As shown in Figure 2F, T6B expression resulted in marked de-repression of miRNA targets in both tissues. 
A

targeting vector

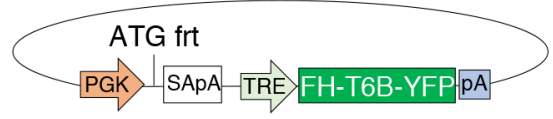

XFlippase
Rosa26 locus
If

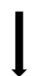

Rosa26 locus fit

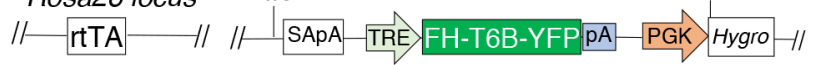

B

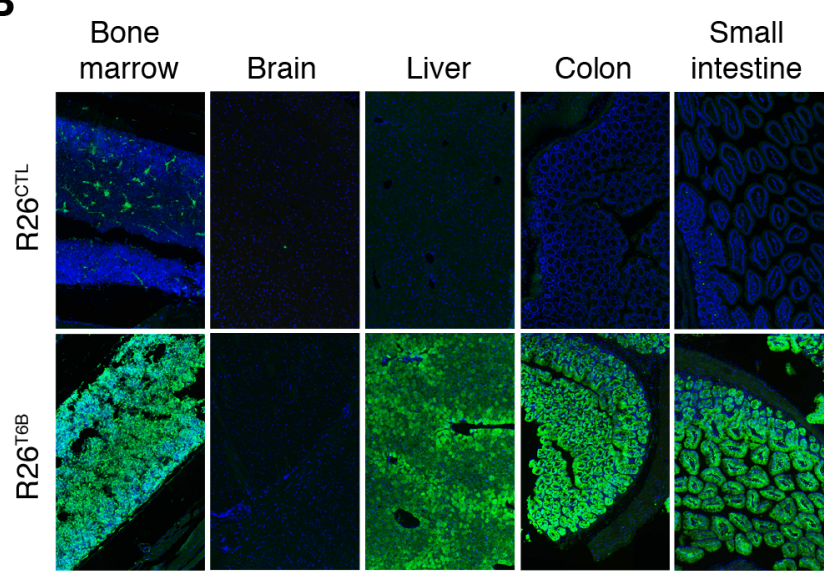

E

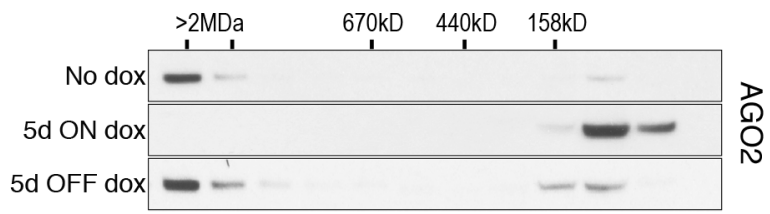

Intestine

miR-200b family predicted targets seed: AAUACUG

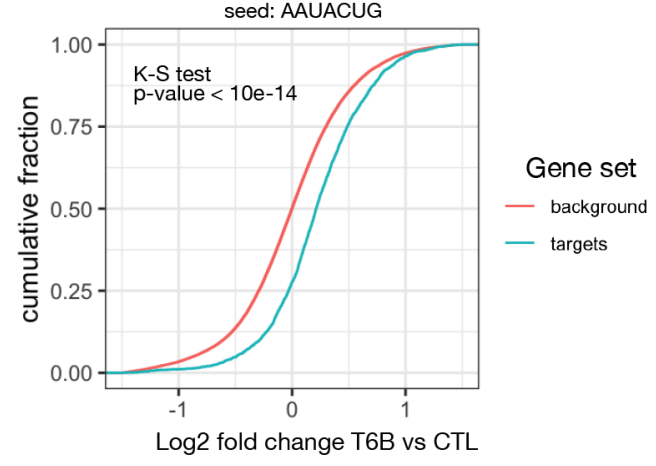

Intestine

miR-26 family predicted targets seed: UCAAGUA

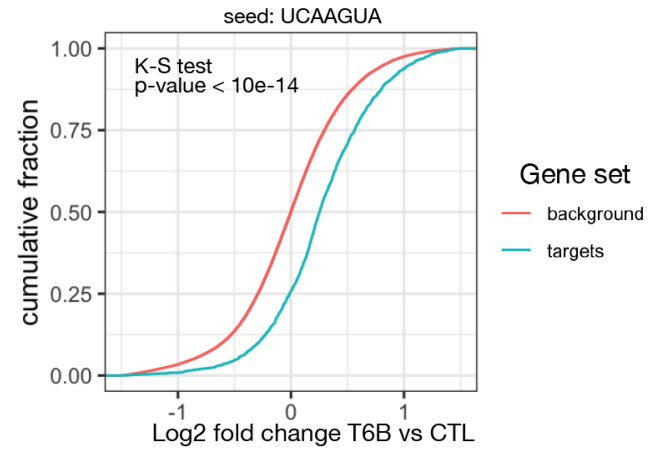

Figure 2. Expression of T6B reversibly blocks miRNA-induced silencing complex (miRISC) assembly and inhibits microRNA (miRNA) function in vivo. (A) Schematic of the targeting strategy to generate the T6B mouse. The construct contains a flippase recognition target site (frt) that allows homing into the Col1a1 locus when electroporated together with a vector expressing the Flippase recombinase into KH2 (Col1a1-frt/Rosa26-rtTA) murine embryonic stem cells. KH2 also express the rtTA trans-activator driven by the endogenous Rosa26 (R26) promoter. (B) Immunofluorescence imaging performed using an anti-YFP antibody, showing T6B expression in a panel of tissues of adult R $26^{\mathrm{T} B \mathrm{~B}}$ mice fed doxycycline for 7 days. Tissues from R26 $6^{\mathrm{CTL}}$ (carrying Figure 2 continued on next page 
Figure 2 continued

the rtTA allele but not the T6B allele) were used as negative controls. (C) Protein lysates from the liver of R26 $6^{\mathrm{T} B}$ mice on or off doxycycline-containing chow for the indicated number of days were resolved by SDS-PAGE and western blotting was performed with anti-HA antibody to detect expression of the T6B transgene. (D) Co-IP experiments using an anti-YFP antibody showing interaction between AGO and T6B in total liver extracts from T6B mice on doxycycline-containing chow. (E) Size-exclusion chromatography (SEC) elution profile of AGO2-containing complexes in liver lysates from T6B mice euthanized at the indicated time points after doxycycline administration. Notice the shift of AGO2 from the high-molecular-weight fractions to the lowmolecular-weight fractions after 5 days of doxycycline treatment and the reconstitution of the full miRISC after removal of doxycycline from the diet. (F, G) Total RNA extracted from the large intestine (F) and the liver (G) of R26 $6^{\mathrm{CTL}}$ and R26 ${ }^{\text {T6B }}$ mice was subjected to RNAseq ( $\mathrm{n}=3 \mathrm{for}$ each strain). Left panel: scatter plot showing the effect of T6B expression on targets of all miRNA families was generated as described in Figure 1D. The abundance of each miRNA family was calculated using dataset from Isakova et al., 2020. Right panel: representative cumulative distribution plot of log2-fold changes in expression of predicted targets of the indicated miRNA families.

The online version of this article includes the following figure supplement(s) for figure 2 :

Source data 1. RNAseq, differential gene expression, colon and liver.

Source data 2. Z-scores and miRNA families abundance, colon and liver.

Source data 3. Unedited blots shown in Figure 2C.

Source data 4. Uncropped blots shown in Figure 2C.

Source data 5. Unedited blots shown in Figure 2D.

Source data 6. Uncropped blots shown in Figure 2D.

Source data 7. Unedited blots shown in Figure 2E.

Source data 8. Uncropped blots shown in Figure 2E.

Figure supplement 1. Expression of FH-T6B-YFP fusion protein in targeted ES clones.

Figure supplement 1-source data 1. Unedited blots shown in Figure 2-figure supplement 1.

Figure supplement 1-source data 2. Uncropped blots shown in Figure 2-figure supplement 1.

Figure supplement 2. Immunofluorescence imaging using a YFP-specific antibody, showing T6B expression in a panel of tissues of adult R26 ${ }^{\mathrm{T} 6 \mathrm{~B}}$ mice (second column) and $\mathrm{CAG}^{\top 6 \mathrm{~B}}$ mice (third column) fed doxycycline-containing diet for 7 days.

Figure supplement 3. Total extracts from the colon of R26 $6^{\text {TSB }}$ mice kept on doxycycline-containing diet for 1 week were immunoprecipitated using an anti-YFP antibody and probed with the indicated antibodies to measure the interaction between the T6B fusion protein and AGO2 in vivo.

Figure supplement 3-source data 1. Unedited blots shown in Figure 2-figure supplement 3.

Figure supplement 3-source data 2. Uncropped blots shown in Figure 2-figure supplement 3.

Figure supplement 4. Size-exclusion chromatography (SEC) fractionation followed by western blotting of total extracts from the liver and large intestine of control and R26 ${ }^{\mathrm{T} B \mathrm{~B}}$ mice treated with doxycycline-containing chow for 7 days.

Figure supplement 4-source data 1. Unedited blots shown in Figure 2-figure supplement 4.

Figure supplement 4-source data 2. Uncropped blots shown in Figure 2-figure supplement 4.

Based on these results, we conclude that T6B expression allows acute and reversible disruption of the miRISC, and concomitant inhibition of miRNA function in vivo.

\section{Consequences of miRISC disruption in adult tissues under homeostatic conditions}

Given the central role of miRNAs in gene regulatory networks, one might expect widespread phenotypes emerging when miRISC function is systemically inhibited. Consistent with this hypothesis, inhibition of miRISC starting either at conception (Figure 3A) or at mid-gestation caused developmental defects and perinatal lethality in R26 $6^{\mathrm{T} B}$ mice (Figure 3B, Figure 3-figure supplement 1). Histological examination of hematoxylin-eosin-stained sections of P0 R $26^{T 6 B}$ pups treated with doxycycline starting at mid-gestation confirmed a general delay in development and reduced growth, but no specific organ defects. Surprisingly, however, adult R26 ${ }^{\text {T6B }}$ mice kept on doxycycline diet for up to 2 months remained healthy and appeared normal upon macroscopic and histopathological examination.

Detailed examination of the intestine confirmed extensive T6B expression in the epithelium and in the mesenchymal compartment (Figure 3-figure supplement 2), but no architectural abnormalities were observed (Figure 3C). Cells in the crypts showed no significant changes in expression pattern of Ki67 protein (Figure 3-figure supplement 3), suggesting that the proliferation and turnover of 


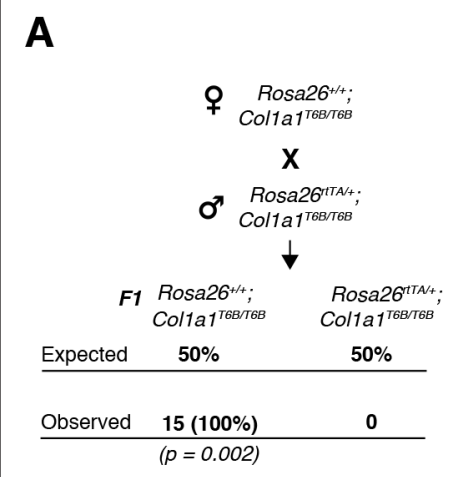

C

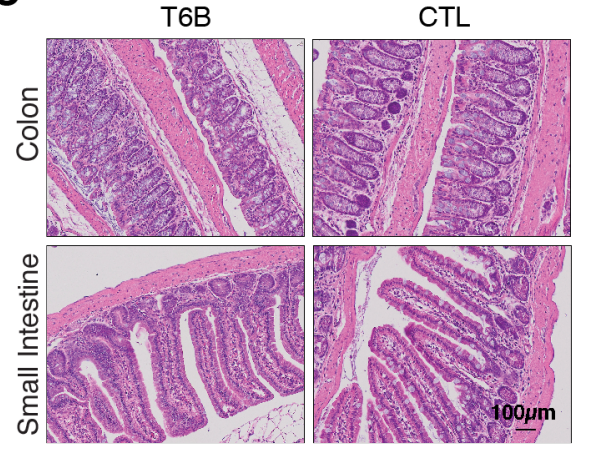

B

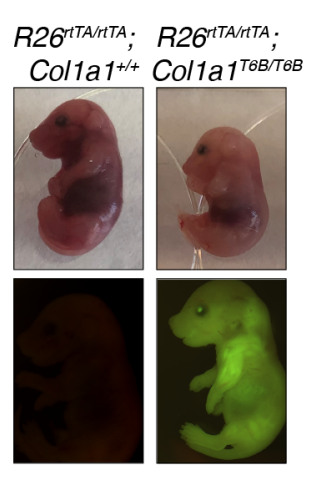

E

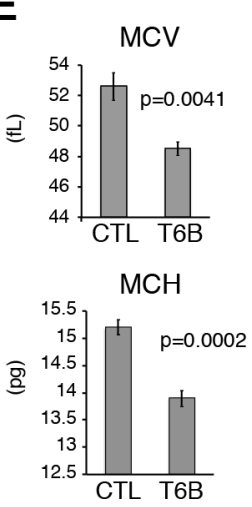

F

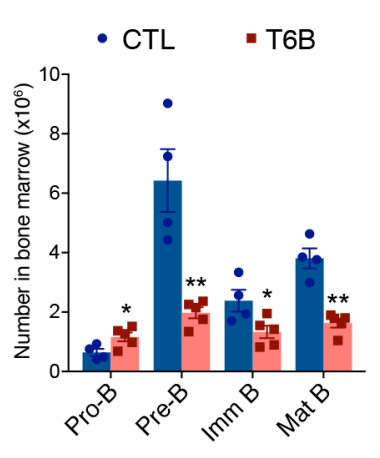

D

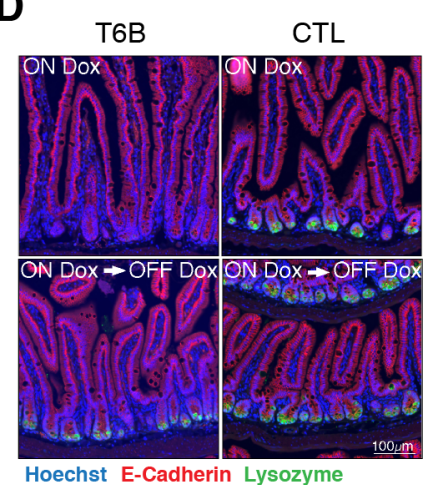

G

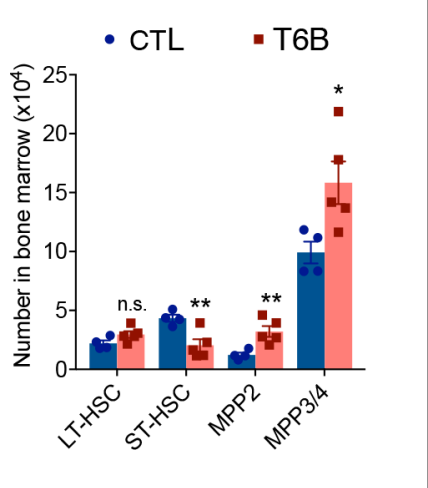

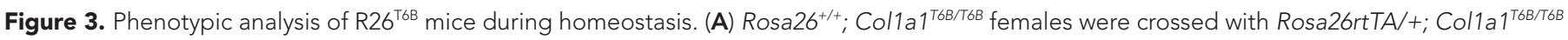
males and doxycycline was administered by chow starting at 0.5 d.p.c. No viable pups positive for both the rtTA and T6B allele were observed ( $n=$ 15, p-value $=0.002$, Fisher's exact test). (B) Pregnant females were kept on doxycycline diet from E13.5 to E18.5 and the pups delivered on E18.5 by

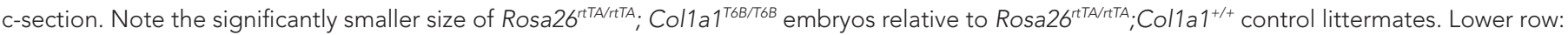
YFP detection by epifluorescence in E18.5 pups of the indicated genotypes. (C) Comparison of intestine architecture in H\&E sections from R26 $6^{T B B}$ and R26 $6^{\text {CTL }}$ mice ( $n=3$ for each genotype) maintained on doxycycline for 2 months. (D) Immunofluorescence imaging of the small intestine of R26 ${ }^{\text {TbB }}$ and R26 $6^{\mathrm{CTL}}$ mice ( $\mathrm{n}=3-5$ for each genotype) kept on doxycycline diet for a month (upper row), showing a reduction in lysozyme expression in Paneth cells in the crypts. Lysozyme expression in R26 ${ }^{\mathrm{T} B}$ mice returned to normal levels upon removal of doxycycline from the diet (lower row). (E) Peripheral blood analysis conducted in $R 26^{T 6 B}$ and $R 26^{C T L}$ mice $\left(R 26^{C T L} n=4 ; R 26^{T 6 B} n=5\right.$ ). (F) Flow cytometric analysis of bone marrow of $R 26^{T 6 B}$ and $R 26^{C T L}$ mice kept on doxycycline diet for 3 weeks showing developmental block at the Pro-B to Pre-B. $p$-Values (from left to right): ${ }^{*} p=0.0348,{ }^{* *} p=0.0023,{ }^{*} p=0.0340$, ${ }^{* \star} \mathrm{p}=0.0004$, unpaired t-test. R26 $6^{\mathrm{CTL}} \mathrm{n}=4 ; \mathrm{R} 26^{\mathrm{T} 6 \mathrm{~B}} \mathrm{n}=5$. (G) Flow cytometry analysis of the bone marrow of control and R26 ${ }^{\mathrm{T} 6 \mathrm{~B}}$ mice kept on doxycycline diet for 3 weeks. $p$-Values (from left to right): $p=0.0994,{ }^{* \star} p=0.0092,{ }^{* *} p=0.0085,{ }^{*} p=0.0312$, unpaired t-test. $R 26^{C T L} n=4 ; R 26^{T 6 B} n=5$.

The online version of this article includes the following source data and figure supplement(s) for figure 3 :

Source data 1. Complete blood counts (CBCs) of whole blood from R26T6B and R26CTL mice.

Figure supplement 1. Effects of FH-T6B-YFP fusion protein expression during development.

Figure supplement 2. Immunofluorescence imaging of the small and large intestine of R $26^{T 6 B}$ and R26 $6^{\mathrm{CTL}}$ mice kept on doxycycline diet for a month.

Figure supplement 3. Sections from the colon and small intestine sections of R26 ${ }^{\mathrm{T}} \mathrm{B}$ and control mice kept on doxycycline-containing diet for 2 months were probed by immunohistochemistry with an anti-Ki67 antibody.

Figure supplement 4. Detection of goblet cells by staining of acidic and neutral mucins in intestine sections from R26 $6^{\mathrm{T} 6 \mathrm{~B}}$ and control mice kept on doxycycline diet for 2 months.

Figure supplement 5. Body weight of $R 26^{T B B}(n=5)$ and control $(n=8)$ female mice was assessed after 2-month administration of doxycyclinecontaining chow.

Figure supplement 6. Representative flow cytometry plots showing the gating strategy for the identification of hematopoietic stem and progenitor cells from whole bone marrow harvested from R26 ${ }^{T 6 B}$ and R26 $6^{\mathrm{CTL}}$ mice maintained on doxycycline diet for 3 weeks.

Figure supplement 7. Representative flow cytometry plots showing the gating strategy for the identification of B cell lineage populations from whole bone marrow harvested from R26 $6^{\mathrm{T} B \mathrm{~B}}$ and R26 $6^{\mathrm{CTL}}$ mice maintained on doxycycline diet for 3 weeks. 
the epithelium are maintained even in the absence of a functional miRISC. No significant change in the number of goblet cells was detected throughout the intestine (Figure 3-figure supplement 4), and mice maintained normal body mass throughout the period of doxycycline treatment (Figure 3figure supplement 5), suggesting that general intestinal functions were not affected.

Although no obvious macroscopic, functional, or architectural abnormalities were caused by T6B expression in the intestine, we observed a reduction in lysozyme expression in Paneth cells in the crypts (Figure 3D, upper row). However, this phenotype was reversible as lysozyme signal in the crypts returned to normal levels when doxycycline was removed from the diet (Figure 3D, lower row), suggesting that T6B expression did not affect neither the viability of intestinal stem cells nor their self-renewal ability.

Complete blood counts showed a modest, but significant, decrease in erythrocytes volume (MCV) and hemoglobin content $\left(\mathrm{MCH}\right.$ ) in R26 ${ }^{\mathrm{T} B \mathrm{~B}} \mathrm{RBCs}$ (Figure 3E, Figure 3-source data 1), analogously to what was reported in mice harboring targeted deletion of miR-451 (Patrick et al., 2010). Flow cytometric analysis of bone marrow showed a threefold depletion in Pre-B cells as well as a significant decrease in immature and mature circulating $B$ cells in $R 26^{T 6 B}$ mice. We also observed a reciprocal increase in the frequency of Pro-B cells in the bone marrow of these animals (Figure 3F, Figure 3figure supplement 6). These results are reminiscent of the partial block in $B$ cell differentiation observed upon deletion of the miR-17-92 cluster (Ventura et al., 2008).

Further characterization of hematopoietic stem cells (HSCs) showed that the number of long-term repopulating hematopoietic stem cells (LT-HSC) was unaffected after 3 weeks of doxycycline exposure. However, we observed a modest decrease in short-term repopulating HSCs (ST-HSCs) and a concomitant increase in multipotent progenitors (MPPs) relative to controls (Figure 3G, Figure 3figure supplement 7 ).

Collectively, these data suggest that in a subset of adult tissues miRISC function can be suppressed with minimal or no consequences on the ability of these tissues to maintain homeostasis.

\section{miRISC disruption impairs the regeneration of injured colon epithelium}

Several studies have shown that the phenotype caused by targeted deletion of individual miRNAs often manifests only after the mutant animals are subjected to 'stress' (Chivukula et al., 2014; Leung and Sharp, 2010; Mendell and Olson, 2012; van Rooij et al., 2007). For example, ablation of miR$143 / 145$ causes no apparent phenotype under homeostasis but severely impairs the ability of the mutant animals to respond to acute damage to the intestinal epithelium (Chivukula et al., 2014).

Prompted by these reports, and by our initial observation that prolonged T6B expression does not substantially affect intestinal homeostasis, we tested the consequences of miRISC disruption on the regenerating intestine. A cohort of $\mathrm{R} 26^{\mathrm{T}} \mathrm{B}^{\mathrm{B}}$ and $\mathrm{R} 26^{\mathrm{CTL}}$ mice were kept on doxycycline-containing diet for 10 days, after which they were treated with dextran sulfate sodium (DSS), which induces severe colitis in mice (Chivukula et al., 2014; Okayasu et al., 1990).

A significant and progressive loss of body mass was observed in both groups during DSS treatment and 2 days following DSS removal (Figure 4A). However, R26 ${ }^{T 6 B}$ mice lost body mass more rapidly than controls and reached critical health conditions 7 days after DSS removal. Three days after DSS removal, control animals started to regain weight, reaching the initial body mass within 5 days after DSS removal (Figure 4A). In contrast, R26 ${ }^{T 6 B}$ mice failed to fully recover (Figure 4A), and all reached a humane endpoint within 5 days after DSS removal from the diet (Figure 4B).

Histological analysis confirmed that DSS treatment induced the disruption of the architecture of the epithelium and the appearance of ulcerative areas to a similar extent in both R2 $6^{\mathrm{T} 6 \mathrm{~B}}$ and R26 $6^{\mathrm{CTL}}$ control mice (Figure 4C, Figure 4-figure supplement 1). In contrast, although 5 days after DSS removal the integrity of the colonic epithelium of control mice was largely reestablished with the exception of isolated dysplastic areas (Figure 4-figure supplement 2), extensive ulcerated regions persisted in the colon of R26 ${ }^{\mathrm{T} 6 \mathrm{~B}}$ mice (Figure 4C). Importantly, we observed the presence of dysplastic epithelium in R26 ${ }^{\mathrm{T} 6 \mathrm{~B}}$ mice during and after DSS treatment, indicating that miRISC disruption does not completely abolish the potential of cells to proliferate, as also confirmed by Ki67 staining (Figure 4D). Therefore, we speculate that other factors, such as impaired stem cell maintenance or differentiation, may be responsible for the increased susceptibility of T6B-expressing colon to DSS treatment.

Chivukula and colleagues have shown that defective intestinal regeneration in the colon of miR143/145-deficient mice is associated with upregulation of the miRNA-143 target IGFBP5 in the 


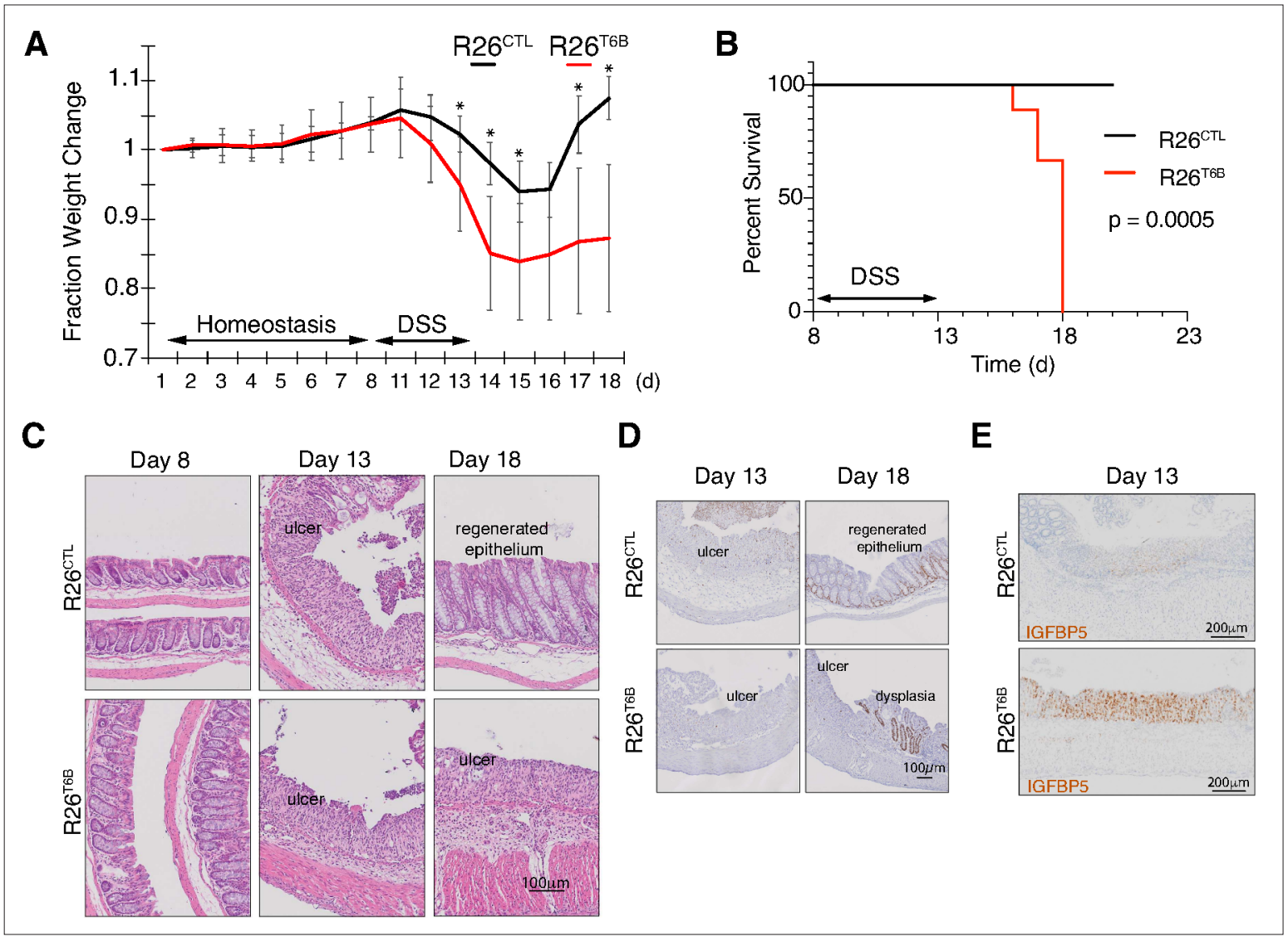

Figure 4. T6B-induced block of miRNA-induced silencing complex (miRISC) assembly leads to impaired intestinal regeneration. (A) R26 ${ }^{\mathrm{T} 6 \mathrm{~B}}$ and R26 $6^{\mathrm{CTL}}$ mice ( $n=6$ for each genotype) kept on doxycycline diet were treated with dextran sulfate sodium (DSS) for 5 days to induce inflammatory colitis and their weight was monitored daily. Data are presented as mean \pm SD. $p$-Values (from left to right): ${ }^{*} p=0.034,{ }^{*} p=0.005,{ }^{*} p=0.029,{ }^{*} p=0.024,{ }^{*} p=0.011$, from unpaired t-test. (B) Kaplan-Meier curves of animals treated with DSS as described in panel (A). p-Value from log-rank test (C) Representative hematoxylin-eosin-stained sections of intestine of R26 ${ }^{T 6 B}$ and R26 $6^{C T L}$ mice ( $n=3$ for each genotype) at different time points pre- and post-DSS treatment. (D) Ki67 immunostaining of section of intestine at the indicated time points. (E) Sections from the large intestine of control and T6B mice euthanized at day 13 were subjected to RNA in situ hybridization with a probe against the IGFBP5 transcript. The results show increased levels of IGFBP5 mRNA in ulcerated areas of $R 26^{T B B}$ as compared to controls ( $n=4$ for each genotype).

The online version of this article includes the following figure supplement(s) for figure 4:

Figure supplement 1. Bar plots showing measurement of colon length, aggregated length of ulcers, percentage of colon with ulcers, area of ulcers, number of immune nodules, and the area of immune nodules performed on H\&E longitudinal sections of colon from R $26^{\mathrm{CTL}}$ and R26 $6^{\mathrm{T} B \mathrm{~B}}$ mice 5 days postdextran sulfate sodium (DSS) treatment.

Figure supplement 2. Representative immunohistochemistry image showing Ki67 signal in control mice $(n=3) 5$ days after dextran sulfate sodium (DSS) treatment was discontinued.

mesenchymal compartment. The increased levels of IGFBP5 protein cause the inhibition of IGF1R signaling in the epithelium through a non-cell-autonomous mechanism, which ultimately prevented epithelial regeneration (Chivukula et al., 2014). Consistent with their findings, in situ hybridization analyses in the colon of DSS-treated R26 ${ }^{\text {T6B }}$ mice showed a significant upregulation of IGFBP5 mRNA in the mesenchymal compartment compared to controls (Figure 4E). The extent of de-repression of IGFBP5 was comparable to that previously observed in miRNA-143/145 knockout mice (Chivukula et al., 2014), providing further evidence that T6B-mediated miRISC disassembly is an effective strategy to globally inhibit miRNA function in vivo.

Collectively, these results support a model whereby miRNA-mediated gene regulation, while dispensable to maintain normal colon homeostasis, becomes critical for its regeneration following acute damage. 


\section{miRISC disruption impairs regeneration of the hematopoietic system}

To further characterize the consequences of miRISC inhibition during tissue regeneration, we explored the possibility that other tissues may adopt a similar dynamic reliance on miRNA function.

Along with the intestinal epithelium, blood is one of the most rapidly turned over tissues in mice. HSCs reside as a predominantly quiescent population in the bone marrow and are rapidly induced to re-enter the cell cycle in response to external cues, such as infection or injury $\mathbf{~} \mathbf{N g}$ and Alexander, 2017). Furthermore, HSCs can be readily isolated by flow cytometry and transplanted, allowing the study of mechanisms underlying regeneration at the single-cell level.

To test the consequences of miRISC disruption in the regenerating hematopoietic system, we treated $\mathrm{R} 26^{\mathrm{T}}{ }_{\mathrm{B}}$ and $\mathrm{R} 26^{\mathrm{CTL}}$ mice on doxycycline-containing diet with a single dose of the cytotoxic drug 5-fluorouracil (5FU). 5-FU selectively depletes rapidly proliferating hematopoietic progenitors and leads to a compensatory increase in LT-HSC proliferation. Flow cytometry analysis of the bone marrow 7 days after $5 \mathrm{FU}$-injection showed that T6B expression prevented this compensatory increase

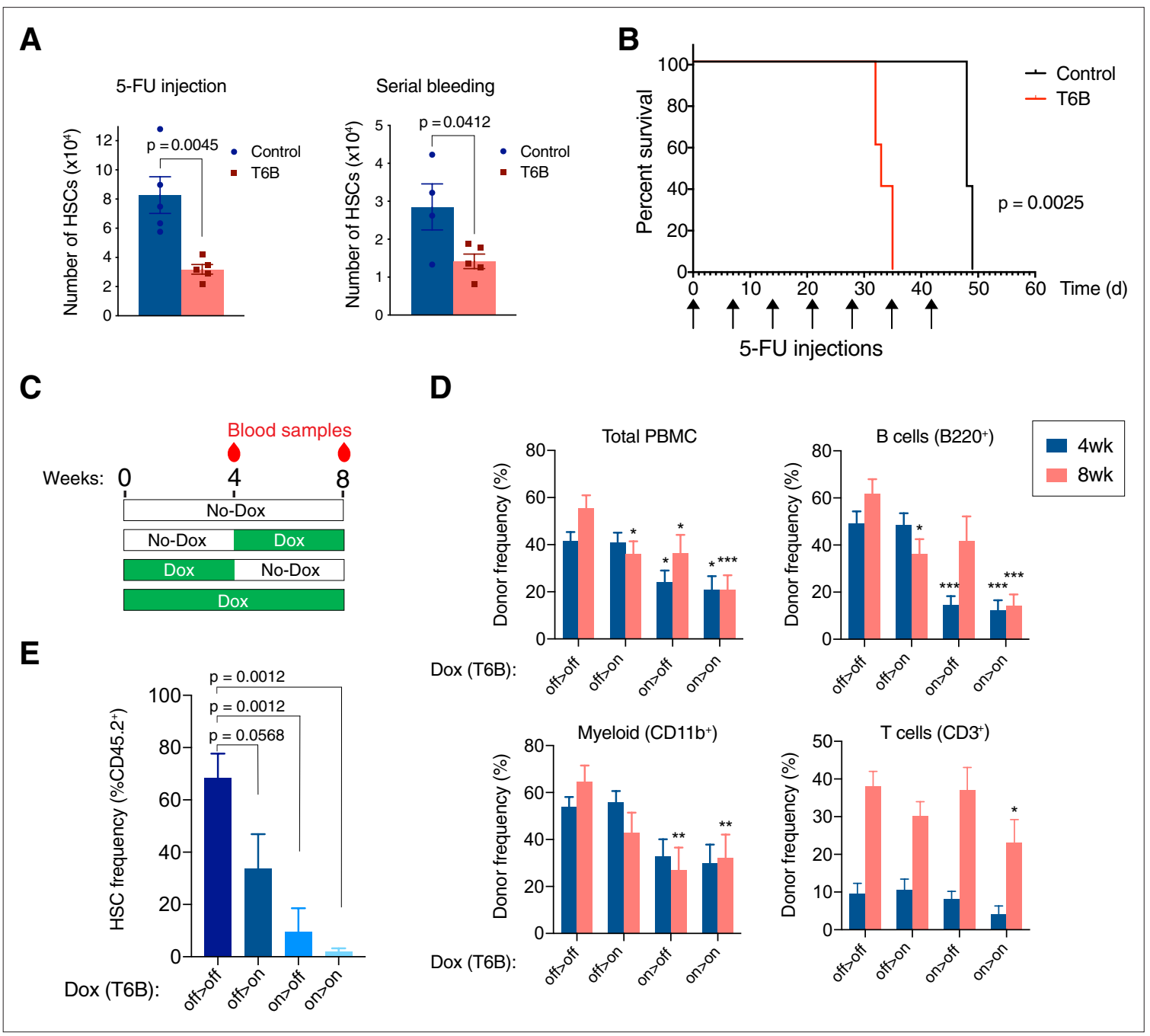

Figure 5. T6B-induced block of miRNA-induced silencing complex (miRISC) assembly impairs the regeneration of the hematopoietic system. (A) Longterm hematopoietic stem cell (HSC) in the bone marrow of R26 ${ }^{T 6 B}$ and R26 $6^{\mathrm{CTL}}$ mice treated with 5-fluorouracil (5-FU) or subjected to repeated bleeding ( $\mathrm{n}$ $=5$ for each genotype). Mice were maintained on doxycycline-containing diet throughout the experiment. (B) Kaplan-Meier plots of R26 $6^{\text {T6B }}(n=5)$ and R26 $6^{\text {CTL }}(n=5)$ mice treated weekly with 5-FU for 7 weeks. (C) Schematic of the bone marrow transplantation experiments: T6B was induced at different time points post-transplantation, and multilineage reconstitution was assessed at the indicated time points by FACS. (D) FACS analysis conducted on the peripheral blood of irradiated recipients transplanted 1:1 with T6B-expressing and wild-type bone marrow, and maintained on doxycycline diet according to scheme shown in panel (C). Data are presented as mean \pm SD. ${ }^{\star} p<0.05,{ }^{\star *} p<0.01,{ }^{\star \star *} p<0.001$, one-way ANOVA. off $>$ off, $n=9$; off $>$ on, $n$ = 10; on > off, $n=8$; on > on, $n=8$. (E) FACS analysis showing the frequency of T6B-extressing HSCs in the bone marrow of transplanted recipient mice kept on doxycycline diet according to scheme shown in panel (C). off > off, $n=5$; off $>$ on, $n=5$; on $>$ off, $n=4$; on $>$ on, $n=5$, one-way ANOVA. 
in LT-HSC. We observed an identical phenotype when $\mathrm{R} 26^{\mathrm{T} 6 \mathrm{~B}}$ and $\mathrm{R} 26^{\mathrm{CTL}}$ mice were bled repeatedly over a 3- week period to induce LT-HSC to re-enter the cell cycle (Figure 5A).

The decreased number of HSCs in the bone marrow of R26 ${ }^{\mathrm{T} 6 \mathrm{~B}}$ mice after a single 5-FU challenge compared to controls suggested that miRISC disruption impaired HSCs' ability to re-enter the cell cycle and regenerate the hematopoietic compartment. Consistent with this hypothesis, when injected with repetitive 5-FU doses, $\mathrm{R} 26^{\mathrm{T} 6 \mathrm{~B}}$ mice showed significantly shorter survival compared to controls (Figure 5B).

To measure the regenerative capacity of HSCs more directly in a context where T6B would only be expressed in hematopoietic cells, we performed competitive transplantation of T6B-expressing $\left(C D 45.2^{+}\right)$and wild-type (CD45.1 $1^{+}$) bone marrows (1:1 ratio) into lethally irradiated hosts. The recipient animals were divided into four groups as shown in Figure 5C: (1) a control group that was never administered doxycycline; (2) a group maintained on a doxycycline-containing diet throughout the duration of the experiment (8 weeks); (3) a group treated with doxycycline starting 4 weeks after transplant; and (4) a group that was on doxycycline for only the first 4 weeks after transplant. Blood samples were taken at 4 and 8 weeks following the start of the experiment for analysis (Figure 5C). This experiment was designed to test the prediction that expression of T6B during the first 4 weeks following transplant, when the regenerative demand is highest and when we hypothesize miRNA-mediated gene repression is required, would more severely affect the ability of donor cells to contribute to the recipient hematopoietic reconstitution compared to T6B expression after homeostasis is reestablished.

Consistent with this prediction, mice that were administered doxycycline in the first 4 weeks posttransplant had significantly fewer CD45.2+ peripheral blood mononuclear cells (PBMCs; Figure 5D). Contribution to the B cell population was particularly impaired by T6B expression, but this was reversed once the recipients were taken off of doxycycline, consistent with the developmental block described earlier (Figure 3D, Figure 3-figure supplement 6). Interestingly, the decrease in total CD45.2 ${ }^{+}$ PBMCs and CD45.2 $2^{+}$myeloid cells was not reversed by doxycycline withdrawal, which suggested that the T6B-expressing CD45.2+ HSCs might have been outcompeted by wild-type CD45.1 $1^{+} \mathrm{HSC}$ in these recipients (Figure 5D). Consistent with this hypothesis, we observed a significant reduction in CD45.2 $2^{+}$HSCs only in the bone marrow of recipient animals that were fed a doxycycline-containing diet in the first 4 weeks post-transplant (Figure 5E).

Taken together, these results support a model where the miRNA-mediated gene regulation is conditionally essential for the maintenance of HSCs during acute regeneration but is largely dispensable under homeostasis.

\section{An essential role for miRNA-mediated gene repression in the skeletal muscle and in the heart}

As previously discussed, we observed low or no expression of T6B in the heart and skeletal muscle of $\mathrm{R}^{2} 6^{\mathrm{T}}{ }_{\mathrm{B}}$ mice treated with doxycycline (Figure 2-figure supplement 2), consistent with previous reports indicating that rtTA expression from the endogenous Rosa26 promoter is tissue restricted (Premsrirut et al., 2011). To extend the analysis of the phenotype caused by the loss of miRISC activity to these tissues, we crossed T6B transgenic mice with the Rosa26-CAGs-rtTA3 strain (Dow et al., 2014) in which the modified chicken beta-actin with CMV-IE enhancer (CAG) promoter (Niwa et al., 1991) drives a more ubiquitous expression of the rtTA variant rtTA3 (hereafter CAG ${ }^{\text {T6B }}$ ). As expected, the pattern and intensity of T6B expression upon dox administration in CAG $^{\text {T6B }}$ mice and $\mathrm{R}^{2} 6^{\mathrm{T} G \mathrm{~B}}$ mice were largely overlapping, except for the heart and the skeletal muscle, for which significant T6B expression was only observed in $\mathrm{CAG}^{\mathrm{T} 6 \mathrm{~B}}$ mice (Figure 6A, Figure 2-figure supplement 2). RNAseq analyses confirmed inhibition of miRNA function in both heart and skeletal muscle of CAG ${ }^{\text {T6B }}$ mice upon dox administration (Figure 6B).

In contrast to $R 26^{\mathrm{T} 6 \mathrm{~B}}$ mice, $\mathrm{CAG}^{\mathrm{T} 6 \mathrm{~B}}$ mice fed a doxycycline-containing diet showed a progressive decline in body mass (Figure 6-figure supplement 1) and died or reached a humane endpoint within 4-6 weeks (Figure 6C). The decrease in body mass was not caused by intestinal malabsorption as, similarly to what was observed in R26 ${ }^{\mathrm{T} 6 \mathrm{~B}}$ mice, we found no evidence of architectural defects throughout the intestine. In contrast, histopathological examination of heart and skeletal muscle showed severe alterations in both organs, including dilated cardiomyopathy and diffuse muscular degeneration (Figure 6D). All mice also showed necro-inflammatory changes in the liver, variable alterations in the pancreas, and increased urea nitrogen and alanine aminotransferase levels in the 
A
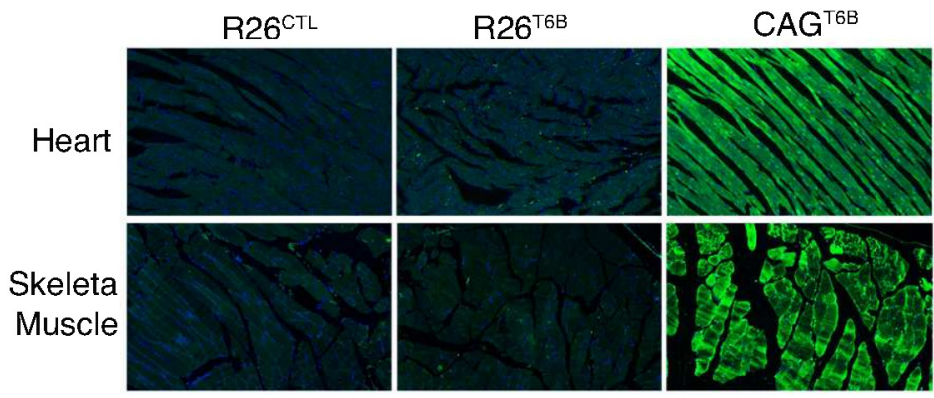

B
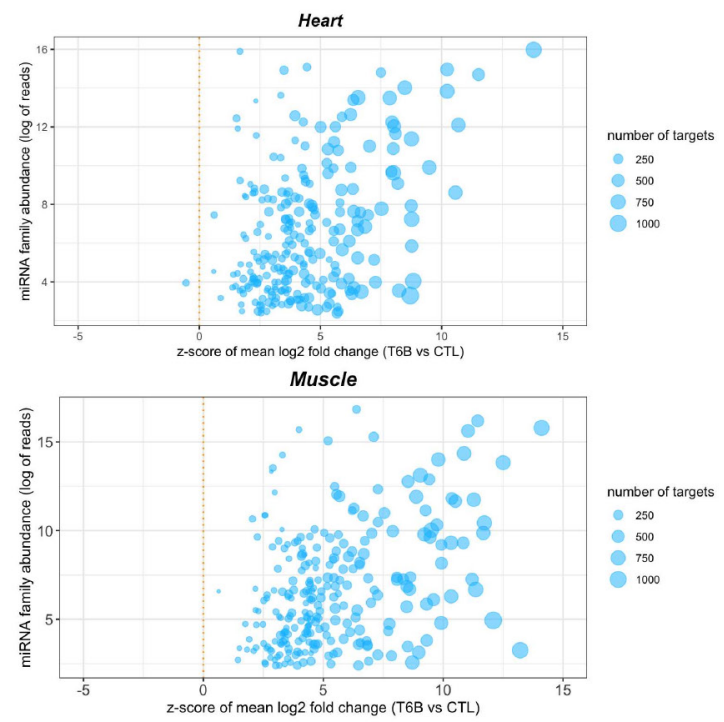

C

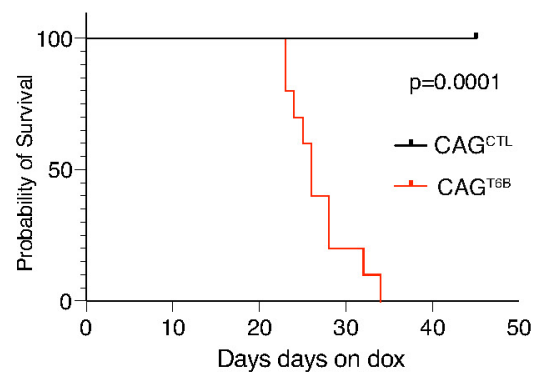

D
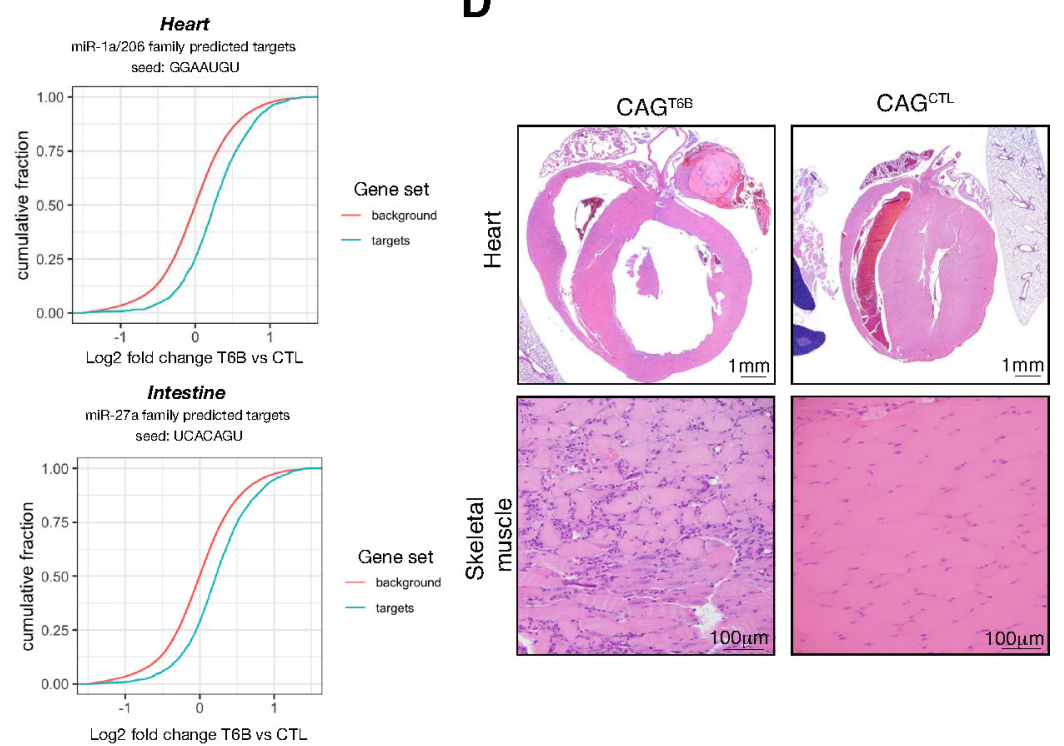

Log2 fold change T6B us CTL

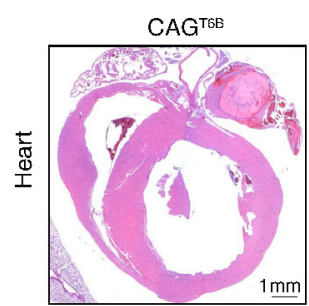

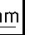

Figure 6. The microRNA (miRNA) pathway is essential in heart and skeletal muscle during homeostasis. (A) Detection of T6B expression with an antiYFP antibody in the heart and skeletal muscle of R26 ${ }^{T 6 B}, C A G^{T 6 B}$, and R26 $6^{\mathrm{CT} L}$ mice maintained on doxycycline-containing diet for 7 days. (B) Total RNA extracted from the heart (upper panel) and the skeletal muscle (lower panel) of CAG ${ }^{\mathrm{CTL}}$ and $\mathrm{CAG}^{\mathrm{T} B \mathrm{~B}}$ mice $(\mathrm{n}=3$ for each strain) maintained on dox for 7 days was analyzed by RNAseq. Left panels: scatter plot showing the effect of T6B expression on targets of conserved miRNA families was generated as described in Figure 1D. The abundance of each miRNA family was calculated using dataset from Isakova et al., 2020. Right panels: representative cumulative distribution plot of log2-fold changes in expression of predicted targets of the indicated miRNA families. (C) Kaplan-Meier curves of CAG ${ }^{\text {T6B }}$ and CAG ${ }^{\text {CTL }}$ mice ( $n=8$ for each genotype) maintained on doxycycline throughout the duration of the experiment. $p$-Value from log-rank test. (D) Upper row: representative H\&E staining showing marked dilation of the four cardiac chambers in hearts of CAG ${ }^{\top 6 B}$ mice compared to controls ( $n=9$ for each genotype). Despite having thinner walls, the histomorphology of ventricular cardiomyofibers was within normal limits. Bottom row: representative H\&E staining showing degenerative and regenerative changes in the skeletal muscle of the hind limbs of $\mathrm{CAG}^{\mathrm{T} B \mathrm{~B}}$ mice compared to controls $(\mathrm{n}=9$ for each genotype).

The online version of this article includes the following figure supplement(s) for figure 6:

Source data 1. RNAseq, heart and muscle.

Source data 2. Z-scores and miRNA family abundance, heart and muscle.

Figure supplement 1. Body weight of $\mathrm{CAG}^{\mathrm{T} B \mathrm{~B}}$ and control mice maintained on doxycycline for up to 45 days was assessed the day on which euthanasia was performed.

Figure supplement 2. Representative H\&E staining showing vasculitis of the pulmonary veins as revealed by inflammatory immune cell infiltration of the vessel wall (arrows).

Figure supplement 3. T6B blocks miRNA activity in sea urchins and zebrafish.

serum. Such alterations are likely secondary to congestive heart failure and/or to severe muscle catabolism as they were not observed in R26 ${ }^{\mathrm{T} 6 \mathrm{~B}}$ mice. Another phenotype that distinguished the R26 $6^{\mathrm{T} 6 \mathrm{~B}}$ strain from the $\mathrm{CAG}^{\mathrm{T} B \mathrm{~B}}$ strain was the presence in the latter of vasculitis of pulmonary veins (Figure 6figure supplement 2). A likely explanation is that these lesions are caused by increased pressure in 
the pulmonary veins secondary to congestive heart failure, but we cannot exclude that they reflect a direct effect of T6B expression on the pulmonary vasculature. Discriminating between these two possibility will require the use of transgenic mice harboring tissue-restricted rtTA transgenes.

The emergence of severe cardiac and skeletal muscle phenotypes, as opposed to the lack of obvious structural and functional abnormalities in most T6B-expressing tissues, points toward the existence of significant differences among adult tissues in their reliance on the miRNA pathway during homeostasis.

\section{Discussion}

We report the generation of a novel genetically engineered mouse strain in which miRISC assembly and function can be temporally and spatially controlled in a reversible manner by a doxycyclineinducible transgene encoding a T6B-YFP fusion protein to address the role(s) miRNA-mediated gene regulation plays in vivo in adult tissues.

Surprisingly, in most adult tissues, we do not find an essential role for miRNA-mediated gene repression in organ homeostasis. A notable exception are the heart and the skeletal muscle, where miRISC inactivation in adult mice results in acute tissue degeneration and death even in the absence of tissue damage or exogenous stress.

Even though miRISC function is not overtly required for the homeostasis of other tissues, we have investigated the consequences of miRNA inhibition in the intestine and in the hematopoietic system of adult mice under homeostatic conditions and during tissue regeneration. These are tissues that periodically respond to external/internal stresses. In both tissues, we have found that miRISC activity is dispensable for homeostasis. However, miRNA function becomes essential during tissue regeneration following acute injury. These results lend experimental support to the hypothesis that a major role for miRNA-mediated gene repression is to support tissue adaptation to stress.

In previous studies where Dicer1 was conditionally ablated in the skeletal muscle of adult mice, muscle regeneration was impaired after acute injury, but no effect on muscle morphology or function was observed during homeostasis (Oikawa et al., 2019a; Oikawa et al., 2019b; Vechetti et al., 2019). An explanation for this difference is that in the Dicer1 conditional knockout experiments miRNA levels were only partially reduced even weeks after Dicer1 ablation, likely reflecting the high stability of these short non-coding RNAs. The T6B mouse strain we describe here overcomes this major limitation and allows the rapid and effective inhibition of miRNA activity independently from the half-life of these molecules.

In this article, we have focused on the role of miRNA-mediated gene repression in adult mice. The same strategy for the acute inhibition of miRISC activity can in principle be applied to other organisms. We have found that expression of T6B in embryos of both sea urchin (Paracentrotus lividus) and zebrafish (Danio rerio) induces developmental defects and gene expression changes consistent with the essential role of the miRNA pathway during development (Ambros and Horvitz, 1984; Chalfie et al., 1981; Lee et al., 1993; Reinhart et al., 2000; Song et al., 2012; Wienholds et al., 2003; Wightman et al., 1993, Figure 6-figure supplement 3). Considering that in vitro T6B efficiently binds to AGO proteins from different non-mammalian organisms (Hauptmann et al., 2015), these findings are not unexpected, yet they highlight the usefulness of the T6B system for dissecting the miRNA pathway in a variety of animal models.

Despite its many advantages, the T6B mouse strain has also some unique limitations that need to be considered when designing and interpreting experiments.

First, although our biochemical and computational analysis of cells and tissues expressing T6B indicates that the peptide can effectively impair miRISC function, we cannot exclude some residual miRISC activity even in cells expressing high levels of the T6B transgene. The observation that we can recapitulate phenotypes observed in mice harboring complete targeted deletion of miR-143/145 miRNAs in the intestine (Chivukula et al., 2014) and of miR-17-92 and miR-451 in the hematopoietic system (Koralov et al., 2008; Patrick et al., 2010; Ventura et al., 2008) is reassuring in this respect. For example, consistent with observations made in the regenerating intestine of miRNA-143/145 knockout mice (Chivukula et al., 2014), we did not record any abnormalities or toxicity during the normal intestinal homeostasis of R26 $6^{\mathrm{T} B \mathrm{~B}}$ mice, whereas T6B expression became lethal during intestinal regeneration. Moreover, in the hematopoietic system, abnormalities were mostly restricted to $B$ cell maturation, which are consistent with a developmental block at the Pro-B to Pre-B transition found 
in mir17-92 knockout mice (Ventura et al., 2008). Finally, we also observed a statistically significant decrease in hematocrit, erythrocyte volume, and hemoglobin content in adult T6B-expressing mice, analogous to what was reported in mice harboring targeted deletion of miR-451 (Patrick et al., 2010).

In contrast, some of our results markedly differ from the results obtained by conditional ablation of Dicer1 in mice. For example, conditional knockout of Dicer1 in the hematopoietic system has been reported to result in the rapid depletion of HSCs (Guo et al., 2010b). Furthermore, the lack of an overt phenotype in the intestine contrasts with previous reports showing that postnatal, conditional deletion of Dicer1 results in depletion of goblet cells (Biton et al., 2011; McKenna et alo, 2010), in addition to abnormal vacuolation and villous distortion in the small intestine (Huang et al., 2012; McKenna et al., 2010). We cannot exclude that these differences are due to an incomplete inactivation of the miRNA pathway in T6B mice, but an alternative explanation is that they reflect the wellcharacterized miRNA-independent functions of DICER.

Another limitation to be considered is the possibility that T6B expression impairs the activity of other complexes in addition to the miRISC. Although RNAseq analysis of cells expressing T6B has not revealed changes that are not explained by loss of miRNA-mediated gene repression and the phenotypes observed are consistent with loss of miRNA activity, this possibility cannot be formally excluded at this time. Further studies to experimentally identify T6B interactors in cells and tissues will be important to formally address this possibility.

In conclusion, we have developed a novel mouse strain that enables investigating the role of miRNA-mediated gene repression in adult organisms. The body of data presented here suggests that in adult animals miRNAs primarily provide for the ability to adaptively change gene expression in response to the physiological and pathological stresses that accompany metazoans' life. It is likely that the specific miRNAs and stresses differ based on the adult organ or tissue being studied, and the model we have generated will be useful to address these important aspects of miRNA biology.

\section{Materials and methods}

Key resources table

\begin{tabular}{|c|c|c|c|c|}
\hline $\begin{array}{l}\text { Reagent type } \\
\text { (species) or resource }\end{array}$ & Designation & Source or reference & Identifiers & Additional information \\
\hline $\begin{array}{l}\text { Strain, strain } \\
\text { background } \\
\text { (Mus musculus) }\end{array}$ & T6B & This paper & Stock \#036470 & $\begin{array}{l}\text { The T6Bwt allele is integrated } \\
\text { in the Col1a1 locus }\end{array}$ \\
\hline $\begin{array}{l}\text { Strain, strain } \\
\text { background } \\
\text { (M. musculus) }\end{array}$ & CD45.1 + C57BL/6 (BoyJ) & Jackson Laboratory & RRID:IMSR_JAX:002014 & $\begin{array}{l}\text { Carries the differential Ptprc } \\
\text { pan leukocyte marker }\end{array}$ \\
\hline $\begin{array}{l}\text { Strain, strain } \\
\text { background } \\
\text { (M. musculus) }\end{array}$ & C57BL/6J & Jackson Laboratory & RRID:IMSR_JAX:000664 & \\
\hline $\begin{array}{l}\text { Strain, strain } \\
\text { background } \\
\text { (M. musculus) }\end{array}$ & Rosa26-CAGs-rtTA3 & Jackson Laboratory & RRID:IMSR_JAX:029627 & $\begin{array}{l}\text { The CAG promoter drives the } \\
\text { expression of rtTA3 }\end{array}$ \\
\hline Cell line (M. musculus) & $\mathrm{KH} 2$ & PMID:16400644 & RRID:CVCL_C317 & Embryonic stem cells \\
\hline Cell line (M. musculus) & DR4 & ATCC & RRID:CVCL_VK72 & Irradiated feeder cells \\
\hline $\begin{array}{l}\text { Transfected construct } \\
\text { (M. musculus) }\end{array}$ & Silencer GAPDH siRNA & Thermo Fisher & \#AM4624 & \\
\hline $\begin{array}{l}\text { Transfected construct } \\
\text { (M. musculus) }\end{array}$ & Negative Control 1 siRNA & Thermo Fisher & \#AM4611 & Nontargeting control \\
\hline Antibody & $\begin{array}{l}\text { Anti-E-cadherin } \\
\text { (mouse monoclonal) }\end{array}$ & $\mathrm{BD}$ & \#610181 & IF: (1:750) \\
\hline Antibody & $\begin{array}{l}\text { Anti-lysozyme } \\
\text { (rabbit polyclonal) }\end{array}$ & Thermo Fisher & \#RB-372-A1 & IF: (1:200) \\
\hline Antibody & $\begin{array}{l}\text { Anti-PH3 } \\
\text { (mouse monoclonal) }\end{array}$ & Cell Signaling & \#970 & IF: (1:200) \\
\hline
\end{tabular}

Continued on next page 
Continued

\begin{tabular}{|c|c|c|c|c|}
\hline $\begin{array}{l}\text { Reagent type } \\
\text { (species) or resource }\end{array}$ & Designation & Source or reference & Identifiers & Additional information \\
\hline Antibody & $\begin{array}{l}\text { Anti-YFP } \\
\text { (rabbit polyclonal) }\end{array}$ & Invitrogen & \#A11122 & IF: (1:250) \\
\hline Antibody & $\begin{array}{l}\text { Anti-Ki67 } \\
\text { (rabbit monoclonal) }\end{array}$ & Cell Signaling & \#12202 & IF: (1:400) \\
\hline Antibody & $\begin{array}{l}\text { Anti-Rabbit IgG, Alexa } \\
\text { Fluor } 488 \\
\text { (goat polyclonal) }\end{array}$ & Thermo Fisher & \#A11034 & IF: (1:250) \\
\hline Antibody & $\begin{array}{l}\text { Anti-mouse IgG2a, Alexa } \\
\text { Fluor } 594 \\
\text { (goat polyclonal) }\end{array}$ & Thermo Fisher & \#A-21135 & IF: $(1: 250)$ \\
\hline Antibody & $\begin{array}{l}\text { Anti-GFP } \\
\text { (chicken polyclonal) }\end{array}$ & Abcam & \#ab13970 & IF: (1:250) \\
\hline Antibody & $\begin{array}{l}\text { Rat lgG } \\
\text { (rat polyclonal) }\end{array}$ & Sigma & \#I-8015 & IF: (1:250) \\
\hline Antibody & $\begin{array}{l}\text { Anti-GW182 } \\
\text { (rabbit polyclonal) }\end{array}$ & Bethyl & \#A302-329A & $\begin{array}{l}\text { WB: (1:1000, } \\
\text { in } 5 \% \text { milk) }\end{array}$ \\
\hline Antibody & $\begin{array}{l}\text { Anti-Ago2 } \\
\text { (rabbit monoclonal) }\end{array}$ & Cell Signaling & \#2897 & WB: $(1: 1000)$ \\
\hline Antibody & $\begin{array}{l}\text { Anti-RPL26 } \\
\text { (rabbit polyclonal) }\end{array}$ & Bethyl & \#A300-686A & WB: $(1: 1000)$ \\
\hline Antibody & $\begin{array}{l}\text { Anti-GAPDH } \\
\text { (mouse monoclonal) }\end{array}$ & Sigma & \#G8795 & WB: (1:2000) \\
\hline Antibody & $\begin{array}{l}\text { anti- } \beta \text {-actin } \\
\text { (mouse monoclonal) }\end{array}$ & Sigma & \#A2228 & WB: $(1: 2000)$ \\
\hline Antibody & $\begin{array}{l}\text { Anti-tubulin } \\
\text { (mouse monoclonal) }\end{array}$ & Sigma-Aldrich & \#T9026 & WB: $(1: 2000)$ \\
\hline Antibody & $\begin{array}{l}\text { Anti-HA } \\
\text { (rabbit monoclonal) }\end{array}$ & Cell Signaling & \#C29F4 & WB: $(1: 1000)$ \\
\hline Antibody & $\begin{array}{l}\text { Anti-rabbit lgG, HRP- } \\
\text { conjugated } \\
\text { (donkey polyclonal) }\end{array}$ & GE Healthcare & \#NA934 & WB: $(1: 10,000)$ \\
\hline Antibody & $\begin{array}{l}\text { Anti-mouse lgG, HRP- } \\
\text { conjugated } \\
\text { (sheep polyclonal) }\end{array}$ & GE Healthcare & \#NA931 & WB: $(1: 10,000)$ \\
\hline Antibody & $\begin{array}{l}\text { Anti-AGO2 } \\
\text { (mouse monoclonal) }\end{array}$ & WAKO & \#011-22033 & IP: $(1 \mu \mathrm{g} / 100 \mu \mathrm{l})$ \\
\hline Antibody & $\begin{array}{l}\text { Anti-AGO1-4 } \\
\text { (mouse monoclonal) }\end{array}$ & EMD Millipore & \#MABE56 & IP: $(1 \mu \mathrm{g} / 100 \mu \mathrm{l})$ \\
\hline Antibody & $\begin{array}{l}\text { Anti-FLAG } \\
\text { (mouse monoclonal) }\end{array}$ & Cell Signaling & \#8146S & IP: $(1 \mu \mathrm{g} / 100 \mu \mathrm{l})$ \\
\hline Antibody & $\begin{array}{l}\text { Anti-HA } \\
\text { (mouse monoclonal) }\end{array}$ & Cell Signaling & \#2367S & IP: $(1 \mu \mathrm{g} / 100 \mu \mathrm{l})$ \\
\hline Antibody & $\begin{array}{l}\text { Anti-lgG1 isotype } \\
\text { (mouse monoclonal) }\end{array}$ & Cell Signaling & \#5415 & IP: $(1 \mu \mathrm{g} / 100 \mu \mathrm{l})$ \\
\hline $\begin{array}{l}\text { Recombinant DNA } \\
\text { reagent }\end{array}$ & $\begin{array}{l}\text { pCAGGS-flpE-puro } \\
\text { (plasmid) }\end{array}$ & Addgene & RRID:Addgene_20733 & $\begin{array}{l}\text { Flippase recombinase- } \\
\text { expressing vector }\end{array}$ \\
\hline $\begin{array}{l}\text { Recombinant DNA } \\
\text { reagent }\end{array}$ & pgk-ATG-frt plasmid & Addgene & RRID:Addgene_20734 & \\
\hline
\end{tabular}

\section{Continued on next page}


Continued

Reagent type (species) or resource

Designation

Source or reference

Identifiers

Additional information

Sequence-based

Col1a1 common_F

This paper

PCR primers

AATCATCCCAGGTG

reagent

Col1a1 wildtype_R

This paper

PCR primers

CACAGCATTGCGG

Sequence-based

reagent

Col1a1 mutant_R

This paper

PCR primers

CTTTGAGGGCTCAT

GAACCTCCCAGG

Sequence-based

reagent

Sequence-based

R26_F

This paper

PCR primers

ATCAAGGAAACCC

TGGACTACTGCG

reagent

This paper

PCR primers

AAAGTCGCTCT

GAGTTGTTAT

Sequence-based

R26a_R

This paper

PCR primers

GCGAAGAGTTTG

reagent

Sequence-based

R26b_R

This paper

PCR primers

TCCTCAACC

reagent

\begin{tabular}{|c|c|c|c|c|}
\hline $\begin{array}{l}\text { Sequence-based } \\
\text { reagent }\end{array}$ & T6B-YFP_F & This paper & PCR primers & $\begin{array}{l}\text { GACTACAAGGACG } \\
\text { ACGATGACAAG }\end{array}$ \\
\hline $\begin{array}{l}\text { Sequence-based } \\
\text { reagent }\end{array}$ & T6B-YFP_R & This paper & PCR primers & $\begin{array}{l}\text { GTTACTTGTACAG } \\
\text { CTCGTCCATG }\end{array}$ \\
\hline $\begin{array}{l}\text { Commercial assay } \\
\text { or kit }\end{array}$ & $\begin{array}{l}\text { RNAscope } 2.5 \mathrm{HD} \\
\text { Detection Reagent, } \\
\text { BROWN }\end{array}$ & $A C D$ & \#320771 & \\
\hline $\begin{array}{l}\text { Commercial assay } \\
\text { or kit }\end{array}$ & RNAScope lgfbp5 Probe & $A C D$ & \#425738 & \\
\hline \multirow[t]{2}{*}{$\begin{array}{l}\text { Commercial assay } \\
\text { or kit }\end{array}$} & Superose 6 10/300 GL & Cytiva & \#GE17-5172-01 & $\begin{array}{l}\text { Now available as } \\
\text { Increase } 10 / 300 \mathrm{GL} \text {, }\end{array}$ \\
\hline & & & & Cytiva \#GE29-0915-96 \\
\hline $\begin{array}{l}\text { Commercial assay } \\
\text { or kit }\end{array}$ & $\begin{array}{l}\text { Novex NuPAGE SDS/ } \\
\text { PAGE gel system }\end{array}$ & Thermo Fisher & \#NP0321 & \\
\hline $\begin{array}{l}\text { Commercial assay } \\
\text { or kit }\end{array}$ & EnVision + HRP & $\begin{array}{l}\text { DAKO, Glostrup, } \\
\text { Denmark }\end{array}$ & \#K401111-2, RRID:AB_2827819 & \\
\hline $\begin{array}{l}\text { Commercial assay } \\
\text { or kit }\end{array}$ & GFP-trap & Chromotek & $\begin{array}{l}\text { \#gtma-10 } \\
\text { RRID:AB_2827592 }\end{array}$ & \\
\hline $\begin{array}{l}\text { Commercial assay } \\
\text { or kit }\end{array}$ & $\begin{array}{l}\text { TruSeq Stranded mRNA } \\
\text { LT Kit, }\end{array}$ & Illumina & \#RS-122-2102 & \\
\hline Software, algorithm & OMERO & PMID:22373911 & RRID:SCR_002629 & \\
\hline Software, algorithm & STAR v2.5.3a & PMID:23104886 & & \\
\hline Software, algorithm & DESeq2 & PMID:25516281 & RRID:SCR_015687 & \\
\hline Software, algorithm & miRbase version 21 & https://www.mirbase.org/ & & \\
\hline Software, algorithm & TargetScan & PMID:26267216 & RRID:SCR_010845 & \\
\hline $\begin{array}{l}\text { Chemical compound, } \\
\text { drug }\end{array}$ & $\begin{array}{l}\text { Doxycyline-containing } \\
\text { Rodent diet }\end{array}$ & Envigo & \#TD01306 & $625 \mathrm{mg} / \mathrm{kg}$ doxycycline \\
\hline $\begin{array}{l}\text { Chemical compound, } \\
\text { drug }\end{array}$ & $\begin{array}{l}\text { Dextran sulfate sodium } \\
\text { (DSS) }\end{array}$ & Cayman Chemical & \#23250 & \\
\hline $\begin{array}{l}\text { Chemical compound, } \\
\text { drug }\end{array}$ & Surgipath Decalcifier I & Leica Biosystems & \#3800400 & Formic acid solution \\
\hline Other & $\begin{array}{l}\text { EDTA-free complete } \\
\text { protease inhibitors }\end{array}$ & Sigma-Aldrich & \#11836170001 & \\
\hline Other & KnockOut DMEM & $\mathrm{GIBCO}$ & \#10829018 & \\
\hline
\end{tabular}

Continued on next page 


\section{Continued}

\begin{tabular}{|c|c|c|c|c|}
\hline $\begin{array}{l}\text { Reagent type } \\
\text { (species) or resource }\end{array}$ & Designation & Source or reference & Identifiers & Additional information \\
\hline Other & Phosphate inhibitors & Roche & \#04906837001 & \\
\hline Other & TRlzol Reagent & Thermo Fisher & \#15596026 & \\
\hline Other & DAPI stain & Sigma-Aldrich & \#62248 & $5 \mu \mathrm{g} / \mathrm{ml}$ \\
\hline Other & Mowiol 4-88 & Calbiochem & \#475904100 GM & Mounting media \\
\hline Other & GlutaMax & GIBCO & \#35050061 & \\
\hline Other & A/G PLUS-Agarose beads & Santa Cruz & \#2003 & \\
\hline Other & RIPA buffer & Sigma-Aldrich & \#R0278 & \\
\hline Other & Lipofectamine RNAiMAX & Thermo Fisher & \#13778100 & Transfection reagent \\
\hline Other & $\begin{array}{l}\text { Alexa Fluor } 488 \text { tyramide } \\
\text { signal amplification } \\
\text { reagent }\end{array}$ & Life Technologies & B40953 & \\
\hline
\end{tabular}

\section{Animal models}

The Rosa26 rtA/rtTA; Col1a1 ${ }^{\text {TGB/TGB }}\left(\mathrm{R} 26^{\text {T6B }}\right.$ ) mice were generated by site-specific integration of the transgene coding for the FLAG-HA-T6B-YFP fusion protein within the Col1a1 locus of KH2 embryonic stem cells (Col1a1-frt/Rosa26 rtTA; Beard et al., 2006). Briefly, the FLAG-HA-T6B-YFP (FH-T6B-YFP) DNA fragment was subcloned into the targeting vector, as described in 'Vectors and molecular cloning.' $A$ mixture of $5 \mu \mathrm{g}$ of the targeting vector and $2.5 \mu \mathrm{g}$ of the pCAGGS-flpE-puro (Addgene \#20733), Flippase recombinase-expressing vector was electroporated into $\mathrm{KH} 2$ cells, using 4D-Nucleofector core unit (Lonza), following the manufacturer's 'primary cells P3' protocol. Selection of targeted clones was initiated $48 \mathrm{hr}$ after electroporation, using $150 \mu \mathrm{g}$ hygromycin per ml of culture medium. 10 days later, individual hygromycin-resistant ES cell clones were analyzed by PCR to confirm correct integration of the knock-in allele. Clones carrying the correctly integrated knock-in allele were genotyped using a three-primer PCR, with the following primers: (1) 5'-AATCATCCCAGGTGCACAGCATTGCGG-3'; (2) 5'-CTTTGAGGGCTCATGAACCTCCCAGG-3'; and (3) 5'-ATCAAGGAAACCCTGGACTACTGCG-3'. A 287-bp-long PCR product indicates successful integration of the transgene into the Col1a1 locus, while a 238-bp-long PCR product indicates a wild-type, untargeted locus. Two independent ES clones were injected into $\mathrm{C} 57 \mathrm{BL} / 6 \mathrm{~J}$ albino blastocysts and backcrossed the resulting chimeras to $\mathrm{C} 57 \mathrm{BL} / 6 \mathrm{~J}$ mice to achieve germline transmission of the recombinant allele. F1 animals were then intercrossed to generate animals expressing rtTA from the Rosa26 locus under control of the Rosa26 endogenous promoter, while expressing the T6B fusion protein from the Col1a1 locus under control of the tetracycline-responsive element (TRE) and the minimal CMV promoter. Animals were genotyped as follows: to assess the presence of the transgene in the Col1a1 locus, PCR was carried out as for the genotyping of $\mathrm{KH} 2$ cells. To assess the presence of the rtTA transgene in the Rosa26 locus, a threeprimer PCR was performed, with the following primers: (1) 5'-AAAGTCGCTCTGAGTTGTTAT-3'; (2) 5'GCGAAGAGTTTGTCCTCAACC-3'; and (3) 5'-CCTCCAATTTTACACCTGTTC-3'. A 350-bp-long PCR product indicates the presence of the rtTA transgene into the Rosa26 locus, while a 297-bp-long PCR product indicates the presence of a wild-type locus. CAG ${ }^{\text {rtTA/rtTA }}$; Col1a1 $1^{\text {T6B/T6B }}\left(C A G^{\text {T6B }}\right)$ mice were generated by backcrossing R26 ${ }^{T 6 B}$ mice with Rosa26-CAGs-rtTA3 mice (a gift from Scott Lowe, MSKCC). In the Rosa26-CAGs-rtTA3 mice, the knock-in allele has the CAG promoter driving the expression of the third-generation reverse tetracycline-regulated transactivator gene (rtTA3), all inserted into the Gt(ROSA)26Sor locus. In vivo doxycycline-dependent expression of the FLAG-HA-T6B-YFP transgene was achieved by feeding mice chow that contained doxycycline at the concentration of $625 \mathrm{mg} / \mathrm{kg}$ (Envigo \#TD01306). Mice were maintained and euthanized in accordance with a protocol approved by the Memorial Sloan Kettering Cancer Center Institutional Animal Care and Use Committee. The T6B transgenic strain has been deposited at the Jackson Laboratory (JAX stock \#036470).

\section{Necropsy, staining, and histopathology}

Mice were euthanized with $\mathrm{CO}_{2}$. Following gross examination, all organs were fixed in $10 \%$ neutral buffered formalin, followed by decalcification of bone in a formic acid solution (Surgipath Decalcifier 
I, Leica Biosystems). Tissues were then processed in ethanol and xylene and embedded in paraffin in a Leica ASP6025 tissue processor. Paraffin blocks were sectioned at $5 \mu \mathrm{m}$, stained with hematoxylin and eosin (H\&E), and examined by a board-certified veterinary pathologist. The following tissues were processed and examined: heart, thymus, lungs, liver, gallbladder, kidneys, pancreas, stomach, duodenum, jejunum, ileum, cecum, colon, lymph nodes (submandibular, mesenteric), salivary glands, skin (trunk and head), urinary bladder, uterus, cervix, vagina, ovaries, oviducts, adrenal glands, spleen, thyroid gland, esophagus, trachea, spinal cord, vertebrae, sternum, femur, tibia, stifle join, skeletal muscle, nerves, skull, nasal cavity, oral cavity, teeth, ears, eyes, pituitary gland, and brain. To detect goblet cells in the intestine, the AB/PAS kit (Thermo Fisher \#87023) was used according to the manufacturer's instructions.

\section{Immunofluorescence}

For the staining of intestine sections shown in Figure 3 and Figure 3-figure supplement 2, formalinfixed, paraffin-embedded (FFPE) slides were deparaffinized and rehydrated according to a standard xylene/ethanol series. After heat-induced epitope retrieval in sodium citrate $(\mathrm{pH} 6)$, tissue sections were permeabilized in triton X-100, blocked, and incubated with the following $1^{\circ}$ antibodies: PH3 (Cell Signaling \#970) at 1:200 dilution; lysozyme (Thermo Fisher \#RB-372-A1) at 1:200 dilution; E-cadherin (BD \#610181) at 1:750 dilution; YFP (Invitrogen \#A11122) at 1:250 dilution; and Ki67 (Cell Signaling $\# 12202$ ) at 1:400 dilution. Next, cells were washed with PBS containing $0.05 \%$ Triton $X$ and incubated with the following $2^{\circ}$ antibodies: goat anti-rabbit IgG, Alexa Fluor 488 (Thermo Fisher \#A11034) at 1:250 dilution; goat anti-mouse IgG2a, Alexa Fluor 594 (Thermo Fisher \#A11029) at 1:250 dilution. For the staining of tissue sections shown in Figures 2 and 4 and Figure 2-figure supplement 2, FFPE tissue sections were cut at $5 \mu \mathrm{m}$ and heated at $58{ }^{\circ} \mathrm{C}$ for $1 \mathrm{hr}$. The antibody against GFP (Abcam, ab13970, $2 \mu \mathrm{g} / \mathrm{ml}$ ) was incubated for $1 \mathrm{hr}$ and detected with Leica Bond RX. Appropriate speciesmatched secondary antibody and Leica Bond Polymer anti-rabbit HRP were used, followed by Alexa Fluor 488 tyramide signal amplification reagent (Life Technologies, B40953). After staining, slides were washed in PBS and incubated in $5 \mu \mathrm{g} / \mathrm{ml}$ 4',6-diamidino-2-phenylindole (DAPI; Sigma-Aldrich) in PBS (Sigma-Aldrich) for $5 \mathrm{~min}$, rinsed in PBS, and mounted in Mowiol 4-88 (Calbiochem). Slides were kept overnight at $-20^{\circ} \mathrm{C}$ before imaging.

\section{Immunohistochemistry}

For immunohistochemistry, deparaffinized sections were subjected to antigen retrieval and processed with the EnVision + HRP kit (K401111-2, DAKO, Glostrup, Denmark) according to the manufacturer's instructions. A primary polyclonal antibody against Ki67 (Cell Signaling \#12202) at 1:400 dilution was diluted in Antibody Diluent (DAKO \#S0809) and incubated overnight at $4{ }^{\circ} \mathrm{C}$. Next, sections were incubated in the provided anti-rabbit HRP-labeled polymer reagent, and detection was performed according to the manufacturer's protocol. Images were acquired using an Olympus BX-UCB slide scanner.

\section{RNA in situ hybridization}

$5 \mu \mathrm{m}$ sections were obtained from FFPE colons from age/sex-matched mice. Before staining, tissue slides were deparaffinized, rehydrated, and permeabilized according to standard procedures. Detection was carried out using RNAscope 2.5 HD Detection Reagent, BROWN (ACD \# 320771), with a specific RNAScope Igfbp5 Probe (ACD \#425738), according to the manufacturer's instructions.

\section{Serum chemistry and hematology}

For serum chemistry, blood was collected into tubes containing a serum separator, the tubes were centrifuged, and the serum was obtained for analysis. Serum chemistry was performed on a Beckman Coulter AU680 analyzer, and the concentration of the following analytes was determined: alkaline phosphatase, alanine aminotransferase, aspartate aminotransferase, creatine kinase, gamma-glutamyl transpeptidase, albumin, total protein, globulin, total bilirubin, blood urea nitrogen, creatinine, cholesterol, triglycerides, glucose, calcium, phosphorus, chloride, potassium, and sodium. $\mathrm{Na} / \mathrm{K}$ ratio and albumin/globulin ratio were calculated. For hematology, blood was collected retro-orbitally into EDTA microtainers. Automated analysis was performed on an IDEXX Procyte DX hematology analyzer. 


\section{DSS treatment and post-DSS treatment quantitative analyses}

Mice kept in doxycycline-containing chow were treated for 5 days with 4\% w/v DSS (FW 40.000; Cayman Chemical \#23250) dissolved in drinking water. Body mass was monitored daily. Measurements of colon length, aggregated length of ulcers, percentage of colon with ulcers, area of ulcers, the number of immune nodules, and the area of immune nodules were obtained using OMERO (https://www.openmicroscopy.org/omero/). Measurements of these parameters were used to estimate the extent of damage and colitis induced by DSS treatment. All measurements were acquired from H\&E-stained colon sections. Ulcer was defined as regions of colon with complete/partial loss of epithelial structure, accompanied by massive immune infiltrates. Colon length was measured by tracing the length of muscular layer of each colon. Length of ulcer was measured as the added length of each ulcerated region along the colon. Ulcer percentage was calculated as the length of ulcer/ length of colon. The area of each individual ulcer was also measured and summed for each animal. Clear immune nodules are visible, showing aggregates of immune cells with high nucleus/cytoplasm ratio. Number and area of the immune nodules were summarized for each animal.

\section{Tissue isolation and total lysates preparation}

Organs extracted from 8- to 12-week-old mice, perfused with PBS, were snap-frozen in liquid nitrogen and stored at $-80{ }^{\circ} \mathrm{C}$ until further processing. To prepare total extract from solid tissues, tissues were pulverized using a mortar, resuspended in $1 \mathrm{ml}$ of lysis buffer per $\mathrm{cm}^{3}$ of tissue, and douncehomogenized with a tight pestle until completely homogenized. Next, extracts were cleared by centrif-

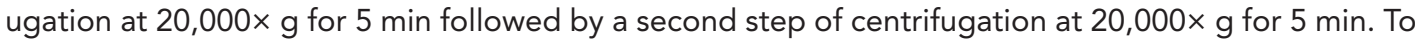
prepare total extracts from cultured cells, pelleted cells were snap frozen in liquid nitrogen and stored at $-80{ }^{\circ} \mathrm{C}$ until further processing. Pellets were then resuspended in lysis buffer, incubated for $10 \mathrm{~min}$ on ice, and cleared by centrifugation at 20,000× $\mathrm{g}$. Two different lysis buffers were used, depending on the specific downstream application. For IP and SEC, lysates were prepared in SEC buffer (150 mM $\mathrm{NaCl}, 10 \mathrm{mM}$ Tris- $\mathrm{HCl}$ pH 7.5, $2.5 \mathrm{mM} \mathrm{MgCl}_{2}, 0.01 \%$ Triton X-100). For western blotting applications, lysates were prepared in RIPA buffer (Sigma-Aldrich \#R0278). Upon usage, both buffers were supplemented with the addition of EDTA-free complete protease inhibitors (Sigma-Aldrich \#11836170001), phosphate inhibitors (Roche \#04906837001), and 1 mM DTT.

\section{Cell lines and culture conditions}

Cell lines were maintained in log-phase growth in a humidified incubator at $37{ }^{\circ} \mathrm{C}, 5 \% \mathrm{CO}_{2}$ prior to experimental manipulation. HCT116 colorectal adenocarcinoma cells were obtained from ATCC prior to this study and tested negative for Mycoplasma and were maintained in McCoy's medium supplemented with 10\% heat-inactivated fetal calf serum (FCS, GIBCO, Cat\#16141079), $10 \mathrm{U} / \mathrm{ml}$ penicillin/streptomycin, and $2 \mathrm{mM} \mathrm{L-glutamine.} \mathrm{MEFs} \mathrm{were} \mathrm{grown} \mathrm{in} \mathrm{Dulbecco's} \mathrm{Modified} \mathrm{Eagle} \mathrm{Medium}$ (DMEM) supplemented with 10\% heat-inactivated FCS (GIBCO), $10 \mathrm{U} / \mathrm{ml}$ penicillin/streptomycin, and $2 \mathrm{mM}$ L-glutamine. $\mathrm{KH} 2$ embryonic stem cells were cultured in gelatin-coated plates in the presence of irradiated DR4 Mouse Embryonic Fibroblasts (Thermo Fisher \#A34966), and maintained in KnockOut DMEM (GIBCO, Cat\#10829018), supplemented with 15\% FCS (GIBCO), GlutaMax (GIBCO Cat\#35050061), 100 MM non-essential amino acids (Sigma-Aldrich Cat\#M7145), $1000 \mathrm{U} / \mathrm{ml}$ leukemia inhibitory factor (LIF, Millipore Cat\#ESG1107), $10 \mathrm{U} / \mathrm{ml}$ penicillin/streptomycin (GIBCO Cat\#15070063), 100 mM 2-mercaptoethanol (Bio-Rad Cat\#1610710), and nucleosides (Millipore Cat\#ES-008-D).

\section{Flow cytometry}

Analysis of bone marrow populations was performed by harvesting femurs and tibiae from euthanized mice. Bone marrow was isolated by centrifugation, resuspended in FACS buffer (PBS with $2 \%$ FCS), and passed through a $40 \mu \mathrm{m}$ cell strainer to make a single-cell suspension. Nonspecific antibody binding was blocked by incubation with $10 \mu \mathrm{g} / \mathrm{ml}$ rat lgG (Sigma \#l-8015) for $15 \mathrm{~min}$ on ice. Antibodies used to identify HSCs included a cocktail of biotinylated lineage antibodies (Gr1, CD11b, TER119, B220, CD3, CD4, CD8), CD117 (c-kit) APC (2B8), Sca-1 (D7) PE-cy7, CD150 PE, and CD48 Pacific Blue. B cell progenitors were identified with the following antibodies: B220, CD19, CD25, CD43, $\operatorname{lgM}$, IgD, and c-kit. For analysis of PBMCs, blood was collected retro-orbitally from live mice into EDTA microtainers. Whole blood was lysed in ACK buffer for $5 \mathrm{~min}$ at room temperature, washed with FACS buffer, and pelleted prior to antibody staining. Mature blood populations were identified with 
the following antibodies: CD45.1, CD45.2, Gr1, CD11b, B220, and CD3. Cells were incubated with primary antibodies for $45 \mathrm{~min}$, washed once with FACS buffer, and incubated with BV711 streptavidin conjugate for $15 \mathrm{~min}$. All incubations were carried out on ice and protected from light. Antibodies were purchased from BioLegend or eBioscience.

\section{Bone marrow transplantation}

8- to 12 -week-old CD45.1 + C57BL/6 (BoyJ) mice (JAX) were lethally irradiated by exposure to 1100 cGy of gamma irradiation from a cesium source, administered in two doses, split $4 \mathrm{hr}$ apart. Bone marrow suspensions from $\mathrm{CAG}^{\top 6 B}\left(\mathrm{CD}^{\mathrm{B}} 5.2^{+}\right)$and BoyJ mice were counted, mixed 1:1, and transferred intravenously by retro-orbital injection into isofluorane-anesthetized, irradiated recipients.

\section{Size-exclusion chromatography (SEC)}

SEC was performed using a Superose 6 10/300 GL prepacked column (GE Healthcare) equilibrated with SEC buffer essentially as previously described (La Rocca et al., 2015; Olejniczak et al., 2013). Briefly, $400 \mu \mathrm{l}(1.5-2 \mathrm{mg})$ of total extracts precleared by centrifugation were run on the SEC column at a flow rate of $0.3 \mathrm{ml} / \mathrm{min}$. $1 \mathrm{ml}$ fractions were collected. Proteins were extracted from each fraction by TCA precipitation following standard procedures and run on SDS-PAGE gels for western blotting analysis.

\section{Western blotting and antibodies}

Western blotting was performed using the Novex NuPAGE SDS/PAGE gel system (Invitrogen). Total cell lysates were run either on 3-8\% Tris-acetate or 4-12\% Bis-Tris precast gels, transferred to nitrocellulose membranes, and probed with antibodies specific to proteins of interest. Detection and quantification of blots were performed on Amersham hyperfilm ECL (Cytiva \#28906839) and developed on film processor SRX-101A (Konica). Antibodies used for western blots were obtained from commercial sources as follows: anti-GW182 (Bethyl \#A302-239A), anti-Ago2 (Cell Signaling \#2897), anti-PABP1 (Cell Signaling \#4992), anti-RPL26 (Bethyl \#A300-686A), anti-GAPDH (Sigma \#G8795), anti- $\beta$-actin (Sigma \#A2228), anti-GFP (Roche \#11814460001), anti-tubulin (Sigma-Aldrich \#T9026), anti-HA (Cell Signaling \#C29F4), anti-rabbit IgG, HRP-conjugated (GE Healthcare \#NA934), and anti-mouse IgG, HRP-conjugated (GE Healthcare \#NA931).

\section{Immunoprecipitation (IP)}

For IP of AGO-T6B complexes from human HCT116 cells, $500 \mu \mathrm{g}$ of lysates in $500 \mu \mathrm{l}$ of SEC buffer were incubated for $3 \mathrm{hr}$ with primary antibodies directed to either AGO proteins (WAKO anti-AGO2 \#011-22033, EMD Millipore anti-panAGO \#MABE56) or directed to T6B-fusion protein (Cell Signaling anti-FLAG \#8146S, Cell Signaling anti-HA \#2367S ) or mouse IgG1 isotype control (Cell Signaling \#5415). Next, lysates were incubated with $20 \mu \mathrm{l}$ of protein A/G PLUS-Agarose beads (Santa Cruz \#2003) for $1 \mathrm{hr}$. For IP of AGO-T6B complexes from mouse tissues, $500 \mu \mathrm{g}$ of lysates in $500 \mu \mathrm{l}$ of SEC buffer were incubated for $2 \mathrm{hr}$ with GFP-trap magnetic agarose beads (Chromotek \#gtma-10) or binding control beads (Chromotek \#bmab-20). The immune complexes were run on SDS-PAGE and analyzed by western blotting.

\section{Vectors and molecular cloning}

The targeting vector expressing the FH-T6B-YFP under control of TRE and CMV minimal promoter was generated from a modified version of the pgk-ATG-frt plasmid (Addgene plasmid \#20734), in which the region of pgk-ATG-frt comprised between the EcoRI site and the Pcil site was substituted with the rabbit $\beta$-globin polyadenylation signal (RBG pA). The FH-T6B-YFP DNA insert was generated by PCR using the plasmid pIRES-Neo-FH-T6B-YFP ${ }^{58}$ as a template. PCR was carried out using the following primers: forward: 5'-GACTACAAGGACGACGATGACAAG-3', reverse: GTTACTTGTACA GCTCGTCCATG. Next, the modified pgk-ATG-frt was cut with Ncol, filled-in to produce blunt ends, dephosphorylated, and ligated to the PCR-generated FH-T6B-YFP DNA fragment according to standard subcloning procedures. A scheme of the cloning strategy is shown as follows: 


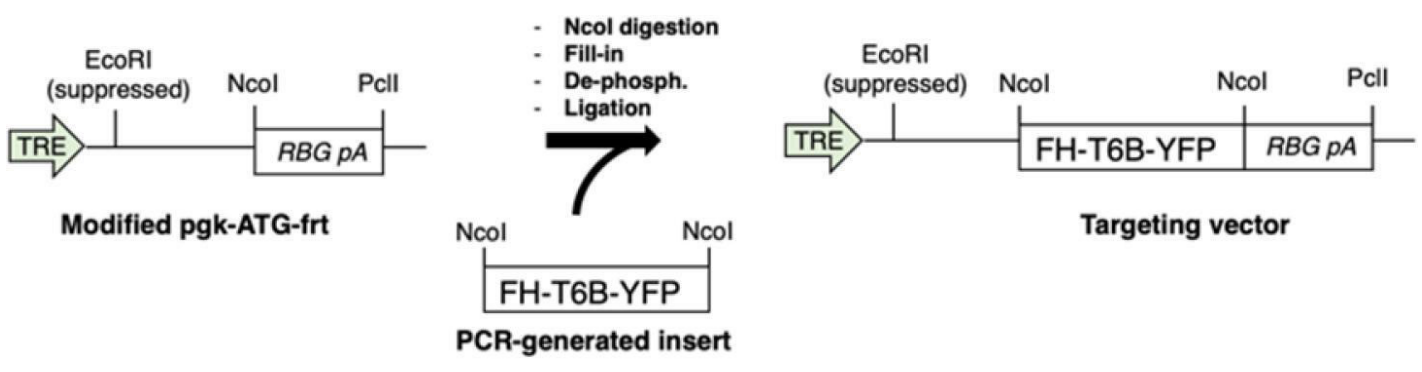

Scheme 1. Cloning strategy for the generation of the targeting vector expressing the FH-T6B-YFP transgene.

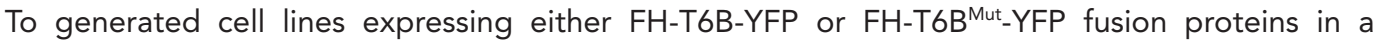
doxycycline-inducible manner, a modified version of the retroviral vector pSIN-TREtight-HA-UbiCrtTA3-IRES-Hygro (hereafter TURN vector, a gift from Scott Lowe) was used to transduce commercially available HCT116 and MEFs cell lines. TURN is an all-in-one Tet-on vector that includes (1) the rtTA3 gene under the human ubiquitin $C$ promoter and (2) the transgene of interest driven by a TRE/CMV promoter. We used the pIRES-Neo-FH-T6B-YFP described in Hauptmann et al., 2015 as a template to generate by PCR the DNA fragments coding either for FH-T6B-YFP or for FH-T6BMut-YFP fusion proteins. DNA fragments were then inserted into the Xhol/EcoRI-digested TURN vector to generate TURN $^{T 6 B}$ and TURN ${ }^{T 6 B m u t}$ vectors used for the transduction of parental HCT116 and MEFs.

\section{Small RNA transfection}

Silencer GAPDH siRNA (Thermo Fisher AM4624) and Silencer Select Negative Control 1 siRNA (Thermo Fisher AM4611) small RNAs were transfected at $10 \mathrm{pM}$ per $1 \times 10^{6}$ cells. MEFs were reverse transfected using Lipofectamine RNAiMAX. Lipofectamine RNAiMAX was combined with $20 \mu \mathrm{M}$ small RNAs at a 4:3 ratio (vol:vol) in Opti-MEM and incubated for $20 \mathrm{~min}$ at room temperature. Trypsinized cells were added to culture dishes containing siRNAs and Lipofectamine RNAiMAX at $3.8 \times 10^{4}$ cells per $\mathrm{cm}^{2}$. Three volumes of complete medium were added to culture dishes, and cells were incubated for 2-3 days before further processing.

\section{Small RNA sequencing}

Total RNA was extracted from MEFs transduced with the retroviral vectors encoding a doxycyclineinducible T6B or T6B ${ }^{\text {mut }}$ transgene and cultured in the presence or absence of doxycycline. Small RNAseq library preparation was as described in Hafner et al., 2011. Briefly, $1 \mu \mathrm{g}$ total RNA was ligated to nine distinct pre-adenylated 26-nt 3'-adapters with a 5-nt barcode using a mutated and truncated Rnl2 followed by urea gel purification and size selection and 5 '-adapter ligation with Rnl1. This ligation reaction was again gel-purified and size-selected for fully ligated product and reverse-transcribed using SuperScript III RT followed by PCR amplification using Taq polymerase for 25 cycles. The final PCR product was separated on a $2 \%$ agarose gel in TBE buffer and extracted using the QIAgen gel extraction kit according to the manufacturer's instructions including all optional steps. After highthroughput sequencing, small RNA reads were aligned to a miRNA genome index built from 1915 murine pre-miRNA sequences from miRbase version 21 (Kozomara et al., 2019; ftp://mirbase.org/ $\mathrm{pub} / \mathrm{mirbase} / 21 /$ ) using Bowtie v2.4.296. Mature miRNA abundance was calculated by counting reads falling within $4 \mathrm{bps}$ at each of the $5^{\prime}$ and $3^{\prime}$ end of the annotated mature miRNAs. miRNA seed family data were downloaded from the TargetScan website at http://www.targetscan.org/cgi-bin/targetscan/ data_download.cgi?db=mmu_71. For miRNA family-level analysis, read counts mapping to members of the same miRNA family were summed up.

\section{RNAseq analysis}

Total RNA from heart, skeletal muscle, colon, and liver of sex-matched littermate animals, and total RNA from cell lines were extracted using TRIzol Reagent (Invitrogen) according to the manufacturer's instructions and subjected to DNase (QIAGEN) treatment. After RiboGreen quantification and quality control by Agilent BioAnalyzer, 500 ng of total RNA with RIN values of 7.0-10 underwent polyA 
selection and TruSeq library preparation according to the instructions provided by Illumina (TruSeq Stranded mRNA LT Kit, Cat\#RS-122-2102), with eight cycles of PCR. Samples were barcoded and run on a HiSeq 4000 in a PE50/50 run using the HiSeq 3000/4000 SBS Kit (Illumina). An average of 34 million paired reads was generated per sample. The percent of mRNA bases averaged $60 \%$ over all samples. Reads were aligned to the standard mouse genome (mm10) using STAR v2.5.3a (Dobin et al., 2013). RNA reads aligned were counted at each gene locus. Expressed genes were subjected to differential gene expression analysis using DESeq2 (Love et al., 2014), and log2-fold changes were determined comparing T6B-expressing tissues to controls.

\section{Z-score calculation}

For each conserved miRNA families, the mean log2-fold change of predicted targets, as defined by TargetScan, compared to the rest of the transcriptome (background), was calculated. The means were converted to z-scores as described by Kim and Volsky, 2005: Z-score $=(\mathrm{Sm}-\mu)^{\star} \mathrm{m}^{1 / 2 \star \partial^{-1}}$, where Sm is the mean of log2-fold changes of genes for a given gene set, $m$ is the size of the gene set, and $\mu$ and $\partial$ are the mean and the standard deviation of background log2-fold change values.

\section{Real-time quantitative PCR}

Real-time quantitative PCR analysis to assess the expression levels of the territorial marker genes involved in the developmental gene regulatory network of the sea urchin was conducted as previously described by Cavalieri et al., 2009. Briefly, total RNA from batches of 150 microinjected embryos was extracted by using the High Pure RNA Isolation kit (Roche). RNA samples were treated with reagents provided by the Turbo DNA-free kit (Ambion) and resuspended in a final volume of $30 \mu$. Reverse transcription into cDNA was performed in an $80 \mu \mathrm{l}$ reaction using random hexamers and the TaqMan Reverse Transcription Reagents kit (Applied Biosystems). The resulting cDNA sample was further diluted, and the equivalent amount corresponding to one embryo was used as template for Q-PCR analysis. Q-PCR experiments were performed from two different batches, and all reactions were run in triplicate on the 7300 Real-Time PCR system (Applied Biosystems) using SYBR Green detection chemistry (Applied Biosystems). ROX was used as a measure of background fluorescence, and MBF-1 and z12 mRNAs were used as internal controls. At the end of the amplification reactions, a 'melting-curve analysis' was run to confirm the homogeneity of all Q-PCR products. Calculations from Q-PCR raw data were performed by the RQ Study software version 1.2.3 (Applied Biosystems) using the comparative $\mathrm{Ct}$ method $(\mathrm{C} t)$. Oligonucleotide primer pairs used for qPCR reactions and amplicon lengths have been described previously (Cavalieri et al., 2008, Cavalieri et al., 2011, Cavalieri and Spinelli, 2014, Cavalieri et al., 2017, Turturici et al., 2018).

\section{Acknowledgements}

This work was funded by the Starr Foundation's Tri-Institutional Stem Cell Initiative (AV, TL, DB, and TT) and by the $\mathrm{NIH} / \mathrm{NCI}$ (grants R01CA149707 and R01CA245507 to AV and P30 CA008748 to CBT). YM was supported by a Medical Scientist Training Program grant from the National Institute of General Medical Sciences of the National Institutes of Health under award number: T32GM007739 to the Weill Cornell/Rockefeller/Sloan Kettering Tri-Institutional MD-PhD Program. We acknowledge the use of the following core facilities at the Memorial Sloan Kettering Cancer Center (MSKCC): The Molecular Cytology Core; The Mouse Genetics Core Facility; The Laboratory of Comparative Pathology, and the Integrated Genomics Operation Core, funded by the NCl Cancer Center Support Grant (CCSG, P30 CA08748), Cycle for Survival, and the Marie-Josée and Henry R Kravis Center for Molecular Oncology. We thank Sebastien Monette and Ileana Miranda for their contribution in the phenotypic analysis of R26 ${ }^{T 6 B}$ and CAG ${ }^{T 6 B}$ mouse strains; Davide Pradella, Rui Gao, Saurabh Yadav, and members of the Benezra laboratory for discussion and suggestions. Finally, we thank Jaqueline Candelier for the handling and processing of tissue samples used in the phenotypic analyses of the R26 ${ }^{T 6 B}$ and $C A G^{T 6 B}$ mouse strains. 


\section{Additional information}

\section{Competing interests}

Craig B Thompson: is a founder of Agios Pharmaceuticals and a member of its scientific advisory board. He is also a former member of the Board of Directors and stockholder of Merck and Charles River Laboratories. He is a named inventor on patents related to cellular metabolism. Potentially relevant patents on which he is a named inventor include the following: (i) L-2-hydroxyglutarate and stress induced metabolism (United States Patent \#10,450,596). (ii) Single diastereomers of 4-fluoroglutamine and methods of their preparation and use (United States Patent \#8,747,809). A complete list of patents can be found at the following link: https://tinyurl.com/y35qvajq. The other authors declare that no competing interests exist.

Funding

\begin{tabular}{lll} 
Funder & Grant reference number & Author \\
\hline National Cancer Institute & R01CA149707 & Andrea Ventura \\
\hline National Cancer Institute & R01CA245507 & Andrea Ventura \\
\hline National Cancer Institute & P30 CA008748 & Craig B Thompson \\
\hline Starr Foundation & & $\begin{array}{l}\text { Gaspare La Rocca } \\
\text { Tullia Lindsten } \\
\text { Andrea Ventura }\end{array}$ \\
\hline $\begin{array}{l}\text { National Institute of } \\
\text { General Medical Sciences }\end{array}$ & T32GM007739 & Yilun Ma \\
\hline National Cancer Institute & P30 CA08748 & Gaspare La Rocca \\
\hline
\end{tabular}

The funders had no role in study design, data collection and interpretation, or the decision to submit the work for publication.

Author contributions

Gaspare La Rocca, Conceptualization, Data curation, Formal analysis, Funding acquisition, Investigation, Methodology, Supervision, Visualization, Writing - original draft, Writing - review and editing; Bryan King, Bing Shui, Conceptualization, Formal analysis, Investigation, Methodology, Visualization, Writing - original draft, Writing - review and editing; Xiaoyi Li, Data curation, Formal analysis, Investigation, Software, Visualization, Writing - original draft, Writing - review and editing; Minsi Zhang, Formal analysis, Investigation, Methodology, Writing - review and editing; Kemal M Akat, Data curation, Investigation, Writing - review and editing; Paul Ogrodowski, Chiara Mastroleo, Kevin Chen, Investigation, Resources; Vincenzo Cavalieri, Investigation, Methodology, Visualization, Writing - review and editing; Yilun Ma, Investigation; Viviana Anelli, Investigation, Methodology; Doron Betel, Data curation, Formal analysis, Funding acquisition, Investigation, Writing - review and editing; Joana Vidigal, Gunter Meister, Conceptualization, Investigation, Methodology, Writing - review and editing; Thomas Tuschl, Conceptualization, Data curation, Formal analysis, Project administration, Writing - review and editing; Craig B Thompson, Tullia Lindsten, Conceptualization, Funding acquisition, Supervision, Writing - review and editing; Kevin Haigis, Conceptualization, Formal analysis, Investigation, Methodology, Supervision, Visualization, Writing - review and editing; Andrea Ventura, Conceptualization, Data curation, Formal analysis, Funding acquisition, Investigation, Methodology, Project administration, Software, Supervision, Visualization, Writing - original draft, Writing - review and editing

Author ORCIDs

Gaspare La Rocca (ii) http://orcid.org/0000-0003-1277-0566

Bing Shui (iD http://orcid.org/0000-0002-5956-130X

Kemal M Akat (ib) http://orcid.org/0000-0002-9012-3551

Kevin Chen (iDib http://orcid.org/0000-0002-0674-1411

Gunter Meister (iD) http://orcid.org/0000-0002-2098-9923

Craig B Thompson (ib) http://orcid.org/0000-0003-3580-2751

Andrea Ventura (iib) http://orcid.org/0000-0003-4320-9907 
Ethics

This study was performed in strict accordance with the recommendations in the Guide for the Care and Use of Laboratory Animals of the National Institutes of Health. All of the animals were handled according to approved institutional animal care and use committee (IACUC) protocols (\#10-10-022) of Memorial Sloan Kettering Cancer Center.

Decision letter and Author response

Decision letter https://doi.org/10.7554/eLife.70948.sa1

Author response https://doi.org/10.7554/eLife.70948.sa2

\section{Additional files}

Supplementary files

- Transparent reporting form

Data availability

Processed sequencing data are included as source data. Fastq files have been deposited to GEO (GEO accession number: GSE179588).

The following dataset was generated:

\begin{tabular}{|c|c|c|c|c|}
\hline Author(s) & Year & Dataset title & Dataset URL & Database and Identifier \\
\hline $\begin{array}{l}\text { Ventura A, Li X, La } \\
\text { Rocca G, King B }\end{array}$ & 2021 & $\begin{array}{l}\text { Inducible and reversible } \\
\text { inhibition of miRNA- } \\
\text { mediated gene repression } \\
\text { in vivo }\end{array}$ & $\begin{array}{l}\text { https://www.ncbi. } \\
\text { nlm.nih.gov/geo/ } \\
\text { query/acc.cgi?acc= } \\
\text { GSE179588 }\end{array}$ & $\begin{array}{l}\text { NCBI Gene Expression } \\
\text { Omnibus, GSE179588 }\end{array}$ \\
\hline
\end{tabular}

The following previously published datasets were used:

\begin{tabular}{lllll}
\hline Author(s) & Year & Dataset title & Dataset URL & Database and Identifier \\
\hline Fehlmann I, Quake K 2020 & $\begin{array}{l}\text { A mouse tissue atlas of } \\
\text { small noncoding RNA }\end{array}$ & $\begin{array}{l}\text { https://www.ncbi. } \\
\text { nlm.nih.gov/geo/ }\end{array}$ & $\begin{array}{l}\text { NCBI Gene Expression } \\
\text { Omnibus, GSE119661 }\end{array}$ \\
& & query/acc.cgi?acc= & \\
& & &
\end{tabular}

\section{References}

Abdellatif M. 2012. Differential expression of microRNAs in different disease states. Circulation Research 110: 638-650. DOI: https://doi.org/10.1161/CIRCRESAHA.111.247437, PMID: 22343558

Ambros V, Horvitz HR. 1984. Heterochronic mutants of the nematode Caenorhabditis elegans. Science 226: 409-416. DOI: https://doi.org/10.1126/science.6494891, PMID: 6494891

Bartel DP. 2009. MicroRNAs: Target Recognition and Regulatory Functions. Cell 136: 215-233. DOI: https://doi. org/10.1016/j.cell.2009.01.002, PMID: 19167326

Bartel DP. 2018. Metazoan MicroRNAs. Cell 173: 20-51. DOI: https://doi.org/10.1016/j.cell.2018.03.006, PMID: 29570994

Beard C, Hochedlinger K, Plath K, Wutz A, Jaenisch R. 2006. Efficient method to generate single-copy transgenic mice by site-specific integration in embryonic stem cells. Genesis 44: 23-28. DOI: https://doi.org/10.1002/ gene.20180, PMID: 16400644

Bernstein E, Kim SY, Carmell MA, Murchison EP, Alcorn H, Li MZ, Mills AA, Elledge SJ, Anderson KV, Hannon GJ. 2003. Dicer is essential for mouse development. Nature Genetics 35: 215-217. DOI: https://doi.org/10.1038/ ng1253, PMID: 14528307

Biton M, Levin A, Slyper M, Alkalay I, Horwitz E, Mor H, Kredo-Russo S, Avnit-Sagi T, Cojocaru G, Zreik F. 2011. Epithelial microRNAs regulate gut mucosal immunity via epithelium-T cell crosstalk. Nature Immunology 12 : 239-246. DOI: https://doi.org/10.1038/ni.1994, PMID: 21278735

Braun JE, Huntzinger E, Fauser M, Izaurralde E. 2011. GW182 proteins directly recruit cytoplasmic deadenylase complexes to mirna targets. Molecular Cell 44: 120-133. DOI: https://doi.org/10.1016/j.molcel.2011.09.007, PMID: 21981923

Cavalieri V, Di Bernardo M, Anello L, Spinelli G. 2008. cis-regulatory sequences driving the expression of the Hbox12 homeobox-containing gene in the presumptive aboral ectoderm territory of the Paracentrotus lividus sea urchin embryo. Developmental Biology 321: 455-469. DOI: https://doi.org/10.1016/j.ydbio.2008.06.006, PMID: 18585371 
Cavalieri V, Melfi R, Spinelli G. 2009. Promoter activity of the sea urchin (Paracentrotus lividus) nucleosomal H3 and $\mathrm{H} 2 \mathrm{~A}$ and linker $\mathrm{H} 1$ alpha-histone genes is modulated by enhancer and chromatin insulator. Nucleic Acids Research 37: 7407-7415. DOI: https://doi.org/10.1093/nar/gkp859, PMID: 19843609

Cavalieri V, Guarcello R, Spinelli G. 2011. Specific expression of a TRIM-containing factor in ectoderm cells affects the skeletal morphogenetic program of the sea urchin embryo. Development 138: 4279-4290. DOI: https://doi.org/10.1242/dev.066480, PMID: 21896632

Cavalieri V, Spinelli G. 2014. Early asymmetric cues triggering the dorsal/ventral gene regulatory network of the sea urchin embryo. eLife 3: e04664. DOI: https://doi.org/10.7554/eLife.04664, PMID: 25457050

Cavalieri V, Spinelli G. 2015a. Ectopic hbox12 expression evoked by histone deacetylase inhibition disrupts axial specification of the sea urchin embryo. PLOS ONE 10: e0143860. DOI: https://doi.org/10.1371/journal.pone. 0143860, PMID: 26618749

Cavalieri V, Spinelli G. 2015b. Symmetry breaking and establishment of dorsal/ventral polarity in the early sea urchin embryo. Symmetry 7: 1721-1733. DOI: https://doi.org/10.3390/sym7041721

Cavalieri V, Geraci F, Spinelli G. 2017. Diversification of spatiotemporal expression and copy number variation of the echinoid hbox12/pmar1/micro1 multigene family. PLOS ONE 12: e0174404. DOI: https://doi.org/10.1371/ journal.pone.0174404, PMID: 28350855

Chalfie M, Horvitz HR, Sulston JE. 1981. Mutations that lead to reiterations in the cell lineages of C. elegans. Cell 24: 59-69. DOI: https://doi.org/10.1016/0092-8674(81)90501-8, PMID: 7237544

Chekulaeva M, Mathys H, Zipprich JT, Attig J, Colic M, Parker R, Filipowicz W. 2011. miRNA repression involves GW182-mediated recruitment of CCR4-NOT through conserved W-containing motifs. Nature Structural \& Molecular Biology 18: 1218-1262. DOI: https://doi.org/10.1038/nsmb.2166

Cheloufi S, Dos Santos CO, Chong MMW, Hannon GJ. 2010. A Dicer-independent miRNA biogenesis pathway that requires Ago catalysis. Nature 465: 576-584. DOI: https://doi.org/10.1038/nature09092

Chen CYA, Zheng DH, Xia ZF, Shyu AB. 2009. Ago-TNRC6 triggers microRNA-mediated decay by promoting two deadenylation steps. Nature Structural \& Molecular Biology 16: 1160-1166. DOI: https://doi.org/10.1038/ nsmb.1709

Chen Y, Boland A, Kuzuoğlu-Öztürk D, Bawankar P, Loh B, Chang CT, Weichenrieder O, Izaurralde E. 2014. A ddx6-cnot1 complex and w-binding pockets in cnot9 reveal direct links between mirna target recognition and silencing. Molecular Cell 54: 737-750. DOI: https://doi.org/10.1016/j.molcel.2014.03.034, PMID: 24768540

Chivukula RR, Shi G, Acharya A, Mills EW, Zeitels LR, Anandam JL, Abdelnaby AA, Balch GC, Mansour JC, Yopp AC, Maitra A, Mendell JT. 2014. An essential mesenchymal function for mir-143/145 in intestinal epithelial regeneration. Cell 157: 1104-1116. DOI: https://doi.org/10.1016/j.cell.2014.03.055, PMID: 24855947

Chong MMW, Rasmussen JP, Rudensky AY, Rundensky AY, Littman DR. 2008. The rnaseiii enzyme drosha is critical in T cells for preventing lethal inflammatory disease. The Journal of Experimental Medicine 205: 2005-2017. DOI: https://doi.org/10.1084/jem.20081219, PMID: 18725527

Chong MM, Zhang G, Cheloufi S, Neubert TA, Hannon GJ, Littman DR. 2010. Canonical and alternate functions of the microRNA biogenesis machinery. Genes \& Development 24: 1951-1960. DOI: https://doi.org/10.1101/ gad. 1953310

Cifuentes D, Xue H, Taylor DW, Patnode H, Mishima Y, Cheloufi S, Ma E, Mane S, Hannon GJ, Lawson ND. 2010. A novel miRNA processing pathway independent of Dicer requires Argonaute2 catalytic activity. Science 328: 1694-1698. DOI: https://doi.org/10.1126/science.1190809, PMID: 20448148

Cimmino A, Calin GA, Fabbri M, lorio MV, Ferracin M, Shimizu M, Wojcik SE, Aqeilan RI, Zupo S, Dono M. 2005. miR-15 and miR-16 induce apoptosis by targeting BCL2. PNAS 102: 13944-13949. DOI: https://doi.org/10. 1073/pnas.0506654102, PMID: 16166262

Cirera-Salinas D, Yu J, Bodak M, Ngondo RP, Herbert KM, Ciaudo C. 2017. Noncanonical function of DGCR8 controls mESC exit from pluripotency. The Journal of Cell Biology 216: 355-366. DOI: https://doi.org/10.1083/ jcb.201606073, PMID: 28100686

Danner J, Pai B, Wankerl L, Meister G. 2017. Peptide-Based Inhibition of miRNA-Guided Gene Silencing Methods in Molecular Biology 1517: 199-210. DOI: https://doi.org/10.1007/978-1-4939-6563-2_14, PMID: 27924484

Dobin A, Davis CA, Schlesinger F, Drenkow J, Zaleski C, Jha S, Batut P, Chaisson M, Gingeras TR. 2013. STAR: ultrafast universal RNA-seq aligner. Bioinformatics 29: 15-21. DOI: https://doi.org/10.1093/bioinformatics/ bts635, PMID: 23104886

Doench JG, Petersen CP, Sharp PA. 2003. siRNAs can function as miRNAs. Genes \& Development 17: 438-442. DOI: https://doi.org/10.1101/gad.1064703

Dow LE, Nasr Z, Saborowski M, Ebbesen SH, Manchado E, Tasdemir N, Lee T, Pelletier J, Lowe SW. 2014. Conditional reverse tet-transactivator mouse strains for the efficient induction of tre-regulated transgenes in mice. PLOS ONE 9: e95236. DOl: https://doi.org/10.1371/journal.pone.0095236, PMID: 24743474

Eichhorn SW, Guo H, McGeary SE, Rodriguez-Mias RA, Shin C, Baek D, Hsu SH, Ghoshal K, Villén J, Bartel DP. 2014. Mrna destabilization is the dominant effect of mammalian micrornas by the time substantial repression ensues. Molecular Cell 56: 104-115. DOI: https://doi.org/10.1016/j.molcel.2014.08.028, PMID: 25263593

Fabian MR, Cieplak MK, Frank F, Morita M, Green J, Srikumar T, Nagar B, Yamamoto T, Raught B, Duchaine TF, Sonenberg N. 2011. miRNA-mediated deadenylation is orchestrated by GW182 through two conserved motifs that interact with CCR4-NOT. Nature Structural \& Molecular Biology 18: 1211-1217. DOI: https://doi.org/10. $1038 /$ nsmb. 2149

Flynt AS, Lai EC. 2008. Biological principles of microRNA-mediated regulation: shared themes amid diversity. Nature Reviews Genetics 9: 831-842. DOI: https://doi.org/10.1038/nrg2455, PMID: 18852696 
Francia S, Michelini F, Saxena A, Tang D, de Hoon M, Anelli V, Mione M, Carninci P, di d'Adda, Fagagna F. 2012. Site-specific DICER and DROSHA RNA products control the DNA-damage response. Nature 488: 231-235. DOI: https://doi.org/10.1038/nature11179, PMID: 22722852

Fukagawa T, Nogami M, Yoshikawa M, Ikeno M, Okazaki T, Takami Y, Nakayama T, Oshimura M. 2004. Dicer is essential for formation of the heterochromatin structure in vertebrate cells. Nature Cell Biology 6: 784-791. DOI: https://doi.org/10.1038/ncb1155, PMID: 15247924

Giles KE, Ghirlando R, Felsenfeld G. 2010. Maintenance of a constitutive heterochromatin domain in vertebrates by a dicer-dependent mechanism. Nature Cell Biology 12: 94-99; . DOI: https://doi.org/10.1038/ncb2010, PMID: 20010811

Gullerova M, Proudfoot NJ. 2012. Convergent transcription induces transcriptional gene silencing in fission yeast and mammalian cells. Nature Structural \& Molecular Biology 19: 1193-1201. DOI: https://doi.org/10.1038/ nsmb.2392, PMID: 23022730

Guo H, Ingolia NT, Weissman JS, Bartel DP. 2010a. Mammalian microRNAs predominantly act to decrease target mRNA levels. Nature 466: 835-840. DOI: https://doi.org/10.1038/nature09267

Guo S, Lu J, Schlanger R, Zhang H, Wang JY, Fox MC, Purton LE, Fleming HH, Cobb B, Merkenschlager M. 2010b. MicroRNA miR-125a controls hematopoietic stem cell number. PNAS 107: 14229-14234. DOI: https:// doi.org/10.1073/pnas.0913574107

Hafner M, Renwick N, Brown M, Mihailovic A, Holoch D, Lin C, Pena JTG, Nusbaum JD, Morozov P, Ludwig J. 2011. RNA-ligase-dependent biases in miRNA representation in deep-sequenced small RNA cDNA libraries. RNA 17: 1697-1712. DOI: https://doi.org/10.1261/rna.2799511, PMID: 21775473

Hauptmann J, Schraivogel D, Bruckmann A, Manickavel S, Jakob L, Eichner N, Pfaff J, Urban M, Sprunck S, Hafner M. 2015. Biochemical isolation of Argonaute protein complexes by Ago-APP. PNAS 112: 11841-11845. DOI: https://doi.org/10.1073/pnas.1506116112, PMID: 26351695

Hebert SS, Papadopoulou AS, Smith P, Galas MC, Planel E, Silahtaroglu AN, Sergeant N, Buee L, De Strooper B. 2010. Genetic ablation of Dicer in adult forebrain neurons results in abnormal tau hyperphosphorylation and neurodegeneration. Human Molecular Genetics 19: 3959-3969. DOl: https://doi.org/10.1093/hmg/ddq311, PMID: 20660113

Huang T-C, Sahasrabuddhe NA, Kim M-S, Getnet D, Yang Y, Peterson JM, Ghosh B, Chaerkady R, Leach SD, Marchionni L, Wong GW, Pandey A. 2012. Regulation of lipid metabolism by dicer revealed through SILAC mice. Journal of Proteome Research 11: 2193-2205. DOI: https://doi.org/10.1021/pr2009884, PMID: 22313051

Huntzinger E, Kuzuoglu-Ozturk D, Braun JE, Eulalio A, Wohlbold L, Izaurralde E. 2013. The interactions of GW182 proteins with PABP and deadenylases are required for both translational repression and degradation of miRNA targets. Nucleic Acids Research 41: 978-994. DOI: https://doi.org/10.1093/nar/gks1078, PMID: 23172285

Isakova A, Fehlmann T, Keller A, Quake SR. 2020. A mouse tissue atlas of small noncoding RNA. PNAS 117: 25634-25645. DOI: https://doi.org/10.1073/pnas.2002277117, PMID: 32978296

Izaurralde E. 2015. Gene Regulation. Breakers and blockers-miRNAs at work. Science 349: 380-382. DOI: https://doi.org/10.1126/science.1260969, PMID: 26206919

Jee D, Yang JS, Park SM, Farmer DT, Wen J, Chou T, Chow A, McManus MT, Kharas MG, Lai EC. 2018. Dual strategies for argonaute2-mediated biogenesis of erythroid mirnas underlie conserved requirements for slicing in mammals. Molecular Cell 69: 265-278. DOI: https://doi.org/10.1016/j.molcel.2017.12.027, PMID: 29351846

JnBaptiste CK, Gurtan AM, Thai KK, Lu V, Bhutkar A, Su MJ, Rotem A, Jacks T, Sharp PA. 2017. Dicer loss and recovery induce an oncogenic switch driven by transcriptional activation of the oncofetal Imp1-3 family. Genes \& Development 31: 674-687. DOI: https://doi.org/10.1101/gad.296301.117

Kaneko H, Dridi S, Tarallo V, Gelfand BD, Fowler BJ, Cho WG, Kleinman ME, Ponicsan SL, Hauswirth WW, Chiodo VA. 2011. DICER1 deficit induces Alu RNA toxicity in age-related macular degeneration. Nature 471: 325-330. DOI: https://doi.org/10.1038/nature09830, PMID: 21297615

Kanellopoulou C, Muljo SA, Kung AL, Ganesan S, Drapkin R, Jenuwein T, Livingston DM, Rajewsky K. 2005. Dicer-deficient mouse embryonic stem cells are defective in differentiation and centromeric silencing. Genes \& Development 19: 489-501. DOI: https://doi.org/10.1101/gad.1248505

Kim SY, Volsky DJ. 2005. PAGE: Parametric analysis of gene set enrichment. BMC Bioinformatics 6: 144. DOI: https://doi.org/10.1186/1471-2105-6-144, PMID: 15941488

Kim YK, Kim B, Kim VN. 2016. Re-evaluation of the roles of drosha, export in 5, and DICER in microrna biogenesis. PNAS 113: E1881-E1889. DOI: https://doi.org/10.1073/pnas.1602532113, PMID: 26976605

Kobayashi T, Papaioannou G, Mirzamohammadi F, Kozhemyakina E, Zhang M, Blelloch R, Chong MW. 2015. Early postnatal ablation of the microRNA-processing enzyme, Drosha, causes chondrocyte death and impairs the structural integrity of the articular cartilage. Osteoarthritis Cartilage 23: 1214-1220. DOI: https://doi.org/ 10.1016/j.joca.2015.02.015

Koralov SB, Muljo SA, Galler GR, Krek A, Chakraborty T, Kanellopoulou C, Jensen K, Cobb BS, Merkenschlager M, Rajewsky N. 2008. Dicer ablation affects antibody diversity and cell survival in the $B$ lymphocyte lineage. Cell 132: 860-874. DOI: https://doi.org/10.1016/j.cell.2008.02.020, PMID: 18329371

Kozomara A, Birgaoanu M, Griffiths-Jones S. 2019. miRBase: from microRNA sequences to function. Nucleic Acids Research 47: D155-D162. DOI: https://doi.org/10.1093/nar/gky1141

Kumar MS, Lu J, Mercer KL, Golub TR, Jacks T. 2007. Impaired microRNA processing enhances cellular transformation and tumorigenesis. Nature Genetics 39: 673-677. DOI: https://doi.org/10.1038/ng2003, PMID: 17401365 
La Rocca G, Olejniczak SH, Gonzalez AJ, Briskin D, Vidigal JA, Spraggon L, DeMatteo RG, Radler MR, Lindsten T, Ventura A. 2015. In vivo, Argonaute-bound microRNAs exist predominantly in a reservoir of low molecular weight complexes not associated with mRNA. PNAS 112: 767-772. DOI: https://doi.org/10.1073/pnas. 1424217112, PMID: 25568082

Lazzaretti D, Tournier I, Izaurralde E. 2009. The C-terminal domains of human TNRC6A, TNRC6B, and TNRC6C silence bound transcripts independently of Argonaute proteins. RNA 15: 1059-1066. DOI: https://doi.org/10. 1261/rna.1606309, PMID: 19383768

Lee RC, Feinbaum RL, Ambros V. 1993. The C. elegans heterochronic gene lin-4 encodes small RNAs with antisense complementarity to lin-14. Cell 75: 843-854. DOI: https://doi.org/10.1016/0092-8674(93)90529-y, PMID: 8252621

Leung AK, Sharp PA. 2010. MicroRNA functions in stress responses. Molecular Cell 40: 205-215. DOI: https:// doi.org/10.1016/j.molcel.2010.09.027, PMID: 20965416

Lian SL, Li SQ, Abadal GX, Pauley BA, Fritzler MJ, Chan EKL. 2009. The C-terminal half of human Ago2 binds to multiple GW-rich regions of GW182 and requires GW182 to mediate silencing. RNA 15: 804-813. DOI: https:// doi.org/10.1261/rna.1229409, PMID: 19324964

Liu JD, Carmell MA, Rivas FV, Marsden CG, Thomson JM, Song JJ, Hammond SM, Joshua-Tor L, Hannon GJ. 2004. Argonaute2 is the catalytic engine of mammalian RNAi. Science 305: 1437-1441. DOI: https://doi.org/ 10.1126/science.1102513, PMID: 15284456

Liu N, Bezprozvannaya S, Williams AH, Qi XX, Richardson JA, Bassel-Duby R, Olson EN. 2008. microRNA-133a regulates cardiomyocyte proliferation and suppresses smooth muscle gene expression in the heart. Genes \& Development 22: 3242-3254. DOI: https://doi.org/10.1101/gad.1738708

Liu Z, Johnson ST, Zhang Z, Corey DR. 2019. Expression of TNRC6 (gw182) proteins is not necessary for gene silencing by fully complementary RNA duplexes. Nucleic Acid Therapeutics 29: 323-334. DOI: https://doi.org/ 10.1089/nat.2019.0815, PMID: 31670606

Love MI, Huber W, Anders S. 2014. Moderated estimation of fold change and dispersion for RNA-seq data with DESeq2. Genome Biology 15: 550. DOI: https://doi.org/10.1186/s13059-014-0550-8, PMID: 25516281

Macias S, Cordiner RA, Gautier P, Plass M, Cáceres JF. 2015. DGCR8 acts as an adaptor for the exosome complex to degrade double-stranded structured rnas. Molecular Cell 60: 873-885. DOI: https://doi.org/10. 1016/j.molcel.2015.11.011, PMID: 26687677

McKenna LB, Schug J, Vourekas A, McKenna JB, Bramswig NC, Friedman JR, Kaestner KH. 2010. MicroRNAs control intestinal epithelial differentiation, architecture, and barrier function. Gastroenterology 139: 16541664. DOI: https://doi.org/10.1053/j.gastro.2010.07.040, PMID: 20659473

Mendell JT, Olson EN. 2012. MicroRNAs in stress signaling and human disease. Cell 148: 1172-1187. DOI: https://doi.org/10.1016/j.cell.2012.02.005, PMID: 22424228

Michelini F, Pitchiaya S, Vitelli V, Sharma S, Gioia U, Pessina F, Cabrini M, Wang Y, Capozzo I, lannelli F. 2017. Damage-induced IncRNAs control the DNA damage response through interaction with DDRNAs at individual double-strand breaks. Nature Cell Biology 19: 1400-1411. DOI: https://doi.org/10.1038/ncb3643, PMID: 29180822

Ng AP, Alexander WS. 2017. Haematopoietic stem cells: past, present and future. Cell Death Discovery 3: 17002. DOI: https://doi.org/10.1038/cddiscovery.2017.2, PMID: 28180000

Nishihara T, Zekri L, Braun JE, Izaurralde E. 2013. miRISC recruits decapping factors to miRNA targets to enhance their degradation. Nucleic Acids Research 41: 8692-8705. DOI: https://doi.org/10.1093/nar/gkt619, PMID: 23863838

Niwa H, Yamamura K, Miyazaki J. 1991. Efficient selection for high-expression transfectants with a novel eukaryotic vector. Gene 108: 193-199. DOI: https://doi.org/10.1016/0378-1119(91)90434-d, PMID: 1660837

Oikawa S, Lee M, Akimoto T. 2019a. Conditional deletion of dicer in adult mice impairs skeletal muscle regeneration. International Journal of Molecular Sciences 20: E5686. DOI: https://doi.org/10.3390/ ijms20225686, PMID: 31766249

Oikawa S, Lee M, Motohashi N, Maeda S, Akimoto T. 2019b. An inducible knockout of dicer in adult mice does not affect endurance exercise-induced muscle adaptation. Am J Physiol-Cell Ph 316: C285-C292. DOI: https:// doi.org/10.1152/ajpcell.00278.2018

Okamura K, Hagen JW, Duan H, Tyler DM, Lai EC. 2007. The mirtron pathway generates microRNA-class regulatory RNAs in Drosophila. Cell 130: 89-100. DOI: https://doi.org/10.1016/j.cell.2007.06.028, PMID: 17599402

Okamura K, Lai EC. 2008. Endogenous small interfering RNAs in animals. Nature Reviews. Molecular Cell Biology 9: 673-678. DOI: https://doi.org/10.1038/nrm2479, PMID: 18719707

Okayasu I, Hatakeyama S, Yamada M, Ohkusa T, Inagaki Y, Nakaya R. 1990. A novel method in the induction of reliable experimental acute and chronic ulcerative colitis in mice. Gastroenterology 98: 694-702. DOI: https:// doi.org/10.1016/0016-5085(90)90290-h, PMID: 1688816

Olejniczak SH, La Rocca G, Gruber JJ, Thompson CB. 2013. Long-lived microRNA-Argonaute complexes in quiescent cells can be activated to regulate mitogenic responses. PNAS 110: 157-162. DOI: https://doi.org/10 1073/pnas.1219958110, PMID: 23248281

Park CY, Choi YS, McManus MT. 2010. Analysis of microrna knockouts in mice. Human Molecular Genetics 19 R169-R175. DOI: https://doi.org/10.1093/hmg/ddq367, PMID: 20805106

Patrick DM, Zhang CC, Tao Y, Yao H, Qi X, Schwartz RJ, Jun-Shen Huang L, Olson EN. 2010. Defective erythroid differentiation in miR-451 mutant mice mediated by 14-3-3zeta. Genes \& Development 24: 1614-1619. DOI: https://doi.org/10.1101/gad.1942810 
Pfaff J, Hennig J, Herzog F, Aebersold R, Sattler M, Niessing D, Meister G. 2013. Structural features of Argonaute-gw182 protein interactions. PNAS 110: E3770. DOI: https://doi.org/10.1073/pnas.1308510110, PMID: 24043833

Premsrirut PK, Dow LE, Kim SY, Camiolo M, Malone CD, Miething C, Scuoppo C, Zuber J, Dickins RA, Kogan SC, Shroyer KR, Sordella R, Hannon GJ, Lowe SW. 2011. A rapid and scalable system for studying gene function in mice using conditional RNA interference. Cell 145: 145-158. DOI: https://doi.org/10.1016/j.cell. 2011.03.012, PMID: 21458673

Rehwinkel J, Behm-Ansmant I, Gatfield D, Izaurralde E. 2005. A crucial role for GW182 and the DCP1:DCP2 decapping complex in miRNA-mediated gene silencing. RNA 11: 1640-1647. DOI: https://doi.org/10.1261/ rna.2191905, PMID: 16177138

Reinhart BJ, Slack FJ, Basson M, Pasquinelli AE, Bettinger JC, Rougvie AE, Horvitz HR, Ruvkun G. 2000. The 21-nucleotide let-7 RNA regulates developmental timing in Caenorhabditis elegans. Nature 403: 901-906. DOI: https://doi.org/10.1038/35002607, PMID: 10706289

Ruby JG, Jan CH, Bartel DP. 2007. Intronic microRNA precursors that bypass Drosha processing. Nature 448 : 83-86. DOI: https://doi.org/10.1038/nature05983, PMID: 17589500

Schirle NT, Sheu-Gruttadauria J, MacRae IJ. 2014. Structural basis for microRNA targeting. Science 346: 608-613. DOI: https://doi.org/10.1126/science.1258040, PMID: 25359968

Sheu-Gruttadauria J, MacRae IJ. 2018. Phase transitions in the assembly and function of human MIRISC. Cell 173: 946-957. DOI: https://doi.org/10.1016/j.cell.2018.02.051, PMID: 29576456

Song JL, Stoeckius M, Maaskola J, Friedlander M, Stepicheva N, Juliano C, Lebedeva S, Thompson W, Rajewsky N, Wessel GM. 2012. Select microRNAs are essential for early development in the sea urchin. Developmental Biology 362: 104-113. DOI: https://doi.org/10.1016/j.ydbio.2011.11.015, PMID: 22155525

Song MS, Rossi JJ. 2017. Molecular mechanisms of Dicer: endonuclease and enzymatic activity. The Biochemical Journal 474: 1603-1618. DOI: https://doi.org/10.1042/BCJ20160759, PMID: 28473628

Stein P, Rozhkov NV, Li F, Cardenas FL, Davydenko O, Vandivier LE, Gregory BD, Hannon GJ, Schultz RM. 2015. Essential Role for endogenous siRNAs during meiosis in mouse oocytes. PLOS Genetics 11: e1005013. DOI: https://doi.org/10.1371/journal.pgen.1005013, PMID: 25695507

Tam OH, Aravin AA, Stein P, Girard A, Murchison EP, Cheloufi S, Hodges E, Anger M, Sachidanandam R, Schultz RM. 2008. Pseudogene-derived small interfering RNAs regulate gene expression in mouse oocytes. Nature 453: 534-538. DOI: https://doi.org/10.1038/nature06904,PMID: 18404147

Till S, Lejeune E, Thermann R, Bortfeld M, Hothorn M, Enderle D, Heinrich C, Hentze MW, Ladurner AG. 2007. A conserved motif in argonaute-interacting proteins mediates functional interactions through the argonaute PIWI domain. Nature Structural \& Molecular Biology 14: 897-903. DOI: https://doi.org/10.1038/nsmb1302

Treiber T, Treiber N, Meister G. 2019. Regulation of microRNA biogenesis and its crosstalk with other cellular pathways. Nature Reviews. Molecular Cell Biology 20: 5-20. DOI: https://doi.org/10.1038/s41580-018-0059-1, PMID: 30228348

Turturici G, La Fiora V, Terenzi A, Barone G, Cavalieri V. 2018. Perturbation of developmental regulatory gene expression by a g-quadruplex DNA inducer in the sea urchin embryo. Biochemistry 57: 4391-4394. DOI: https://doi.org/10.1021/acs.biochem.8b00551

van Rooij E, Sutherland LB, Qi X, Richardson JA, Hill J, Olson EN. 2007. Control of stress-dependent cardiac growth and gene expression by a microRNA. Science 316: 575-579. DOI: https://doi.org/10.1126/science. 1139089, PMID: 17379774

Vechetti IJ, Wen Y, Chaillou T, Murach KA, Alimov AP, Figueiredo VC, Dal-Pai-Silva M, McCarthy JJ. 2019. Life-long reduction in myomir expression does not adversely affect skeletal muscle morphology. Scientific Reports 9: 5483. DOI: https://doi.org/10.1038/s41598-019-41476-8, PMID: 30940834

Ventura A, Young AG, Winslow MM, Lintault L, Meissner A, Erkeland SJ, Newman J, Bronson RT, Crowley D, Stone JR. 2008. Targeted deletion reveals essential and overlapping functions of the miR-17 through 92 family of miRNA clusters. Cell 132: 875-886. DOI: https://doi.org/10.1016/j.cell.2008.02.019, PMID: 18329372

Wang YM, Medvid R, Melton C, Jaenisch R, Blelloch R. 2007. DGCR8 is essential for microRNA biogenesis and silencing of embryonic stem cell self-renewal. Nature Genetics 39: 380-385. DOI: https://doi.org/10.1038/ ng1969, PMID: 17259983

Wienholds E, Koudijs MJ, van Eeden FJ, Cuppen E, Plasterk RH. 2003. The microRNA-producing enzyme Dicer1 is essential for zebrafish development. Nature Genetics 35: 217-218. DOI: https://doi.org/10.1038/ng1251, PMID: 14528306

Wightman B, Ha I, Ruvkun G. 1993. Posttranscriptional regulation of the heterochronic gene lin-14 by lin-4 mediates temporal pattern formation in C. elegans. Cell 75: 855-862. DOI: https://doi.org/10.1016/0092-8674( 93)90530-4, PMID: 8252622

Williams AH, Valdez G, Moresi V, Qi XX, McAnally J, Elliott JL, Bassel-Duby R, Sanes JR, Olson EN. 2009. Microrna-206 delays ALS progression and promotes regeneration of neuromuscular synapses in mice. Science 326: 1549-1554. DOI: https://doi.org/10.1126/science.1181046, PMID: 20007902

Yang JS, Lai EC. 2011. Alternative miRNA biogenesis pathways and the interpretation of core miRNA pathway mutants. Molecular Cell 43: 892-903. DOI: https://doi.org/10.1016/j.molcel.2011.07.024, PMID: 21925378

Yekta S, Shih IH, Bartel DP. 2004. MicroRNA-directed cleavage of HOXB8 mRNA. Science 304: 594-596. DOI: https://doi.org/10.1126/science.1097434, PMID: 15105502

Zeng Y, Yi R, Cullen BR. 2003. MicroRNAs and small interfering RNAs can inhibit mRNA expression by similar mechanisms. PNAS 100: 9779-9784. DOI: https://doi.org/10.1073/pnas.1630797100, PMID: 12902540 
Zielezinski A, Karlowski WM. 2015. Early origin and adaptive evolution of the GW182 protein family, the key component of RNA silencing in animals. RNA Biology 12: 761-770. DOI: https://doi.org/10.1080/15476286. 2015.1051302, PMID: 26106978

Zipprich JT, Bhattacharyya S, Mathys H, Filipowicz W. 2009. Importance of the C-terminal domain of the human GW182 protein TNRC6C for translational repression. RNA 15: 781-793. DOI: https://doi.org/10.1261/rna. 1448009, PMID: 19304925 